\title{
Nanoparticles as energy donors and acceptors in bionanohybrid systems*
}

\author{
Jakub Sławski and Joanna Grzyb $₫$ \\ Department of Biophysics, Faculty of Biotechnology, University of Wroclaw, Wrocław, Poland
}

The bionanohybrids are the junctions of at least two objects of different origin: abiotic and biotic. The abiotic part is a nanoparticle (often a fluorescent quantum dot), the biotical one may be a protein (especially fluorescent one or redox-active one), nucleic acid, carbohydrate as well as a simple organic molecule. When such a junction undergoes illumination, the energy transfer between the partners is possible. The nanoparticles, depending on their characteristics, may be donors, acceptors or mediators of the energy transfer. In most cases, the mechanism of the transfer is the Förster resonance energy transfer (FRET) or the electron transfer (ET). Here, we reviewed the newest achievements in the field with special attention paid to those bionanohybrids which allow FRET or ET. Such nanohybrids are important not only for exploration of the mechanism of the partner interaction but mainly for working out nanobiodevices for biosensing and nanotools for modern therapies.

Keywords: nanoparticles; resonance energy transfer; electron transfer; fluorescence; proteins

Received: 18 October, 2019; revised: 11 December, 2019; accepted: 13 December, 2019; available on-line: 28 December, 2019

『e-mail: joanna.grzyb@uwr.edu.pl

*Acknowledgements of Financial Support:

The costs of the article published as a part of the 44th FEBS Congress Kraków 2019 - From molecules to living systems block are financed by the Ministry of Science and Higher Education of the Republic of Poland (Contract 805/P-DUN/2019).

Authors acknowledge the support from National Science Centre, Poland, under Sonata Bis grant no. UMO-2016/22/E/NZ1/00673 Abbreviations: AuNP, gold nanoparticle; AgNP, silver nanoparticle; BRET, bioluminescence resonance energy transfer; CRET, chemiluminescence resonance energy transfer; $C D$, carbon nanodot; $d E T$, direct electron transfer; $\mathrm{ET}$, electron transfer; $\mathrm{E}_{m}$, midpoint potential; FRET, Förster resonance energy transfer; GQD, graphene quantum dot; iET, indirect electron transfer; LUMO, lowest unoccupied molecular orbital; PRET, plasmon resonance energy transfer; $\mathrm{pET}$, photoinduced electron transfer; QD, quantum dot; UCNP, upconverting nanoparticle

\section{THE BIONANOHYBRIDS AND POSSIBLE MECHANISMS OF ENERGY TRANSFER}

The bionanohybrids are the nanoscale junctions of at least two objects of a different origin. One partner in a hybrid is biological, while the second one is abiotic. Nanoscale means that the objects are smaller than $100 \mathrm{~nm}$ in at least one of their dimensions. For biological word, it may include virtually all possible types of molecules. The most used are proteins, but there are also sugarand oligonucleotide-based nanohybrids. The abiotic partners are nanoparticles or broadly - nanomaterials. The most interesting case here are semiconductor quantum dots, especially colloidal ones. There are also carbon- based nanomaterials and nanoparticles of other metals, like silver or gold. The nanoparticles are characterised in more detail in the following paragraph. The aim of this review was to characterize the bionanohybrids that function with energy transfer between the partners. We can distinguish two mechanisms of such a transfer - the resonance energy transfer, with main example of Förster resonance energy transfer (FRET) (Jones \& Bradshaw, 2019), also known as electronic energy transfer, and redox process of electron transfer (ET), or charge transfer process with electron/hole exchange. For every type of energy transfer, one molecule is a donor, while the second one is an acceptor. In more complicated cases, there may be mediators, playing both the role of an acceptor and a donor. In general, the energy transfer is possible when the energy of the lowest unoccupied molecular orbital (LUMO) of the donor is higher than the energy level of LUMO of the acceptor. It can be illustrated in a simple way with so-called Jablonski diagram (Fig. 1). In FRET, there is no exchange of electron/ hole between the donor and acceptor. The excited electrons recombine to their ground state with the emission of a virtual photon, which is transferred to the acceptor, causing its excitation. Dipole-dipole couplings between donor and acceptor are facilitating the process. FRET efficiency depends on the distance between the donor and acceptor. For each FRET pair, there is a specific distance for $50 \%$ transfer efficiency, called $\mathrm{R}_{0}$. This value is calculated from the dipole orientation factor of the donor and acceptor, the refractive index of the medium, fluorescence quantum yield of the donor and the spectral overlap between the donor emission and acceptor absorption spectra. The last requirement is simply the representation of compatibilities of orbitals energy levels. The FRET efficiency may be also analysed based on the changes in the donor fluorescence quantum yield. The equations and more detailed analysis may be found elsewhere (Lakowicz, 2007). The energy transfer types, related to FRET, are bioluminescence resonance energy transfer (BRET) and chemiluminescence resonance energy transfer (CRET). The base of the mechanism is the same as in FRET, the only difference is the origin of the donor excitation - the event of photon absorption in FRET or the excitation due to chemical (CRET) or biochemical (BRET) transformations. In the basic description, formulated by Förster and allowing FRET to be a molecular ruler, the efficiency decreases with $6^{\text {th }}$ power of distance $\left(\mathrm{R}^{\mathrm{G}}\right)$. Based on the quantum electrodynamics (QED), the description of this energy transfer contains also the dependency on $\mathrm{R}^{2}$, dominating in the long-range, and $\mathrm{R}^{4}$, for intermediate distances (Jones \& Bradshaw, 2019). FRET pairs might be also moderately influenced by plasmonic nanoparticles (Bohlen et al., 2019). Plas- 


\section{A}

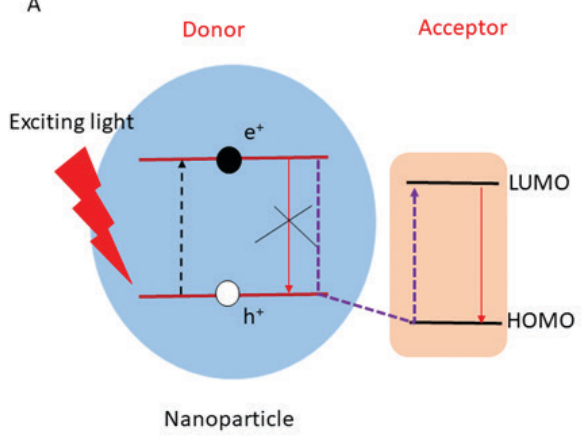

Nanoparticle

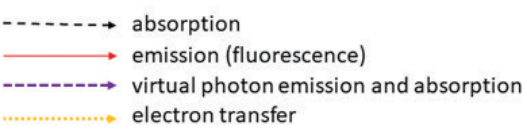

B

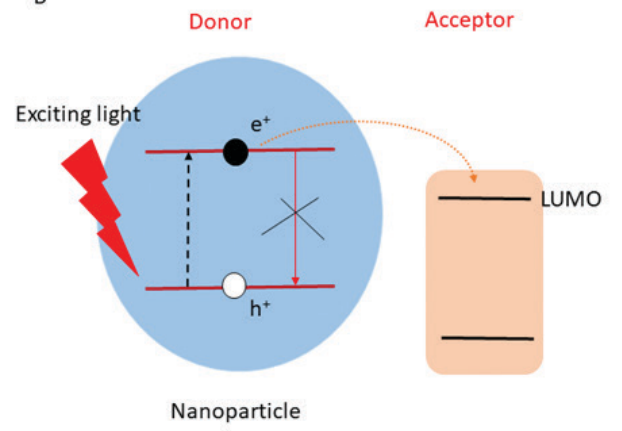

Donor

Acceptor

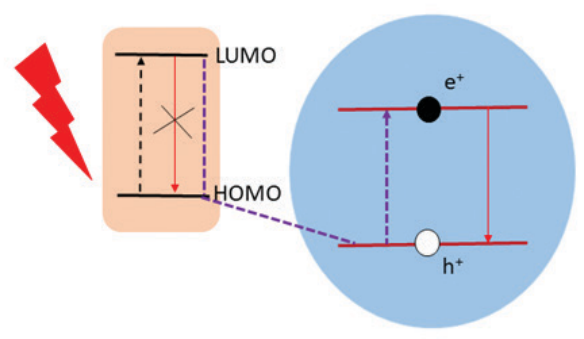

Nanoparticle

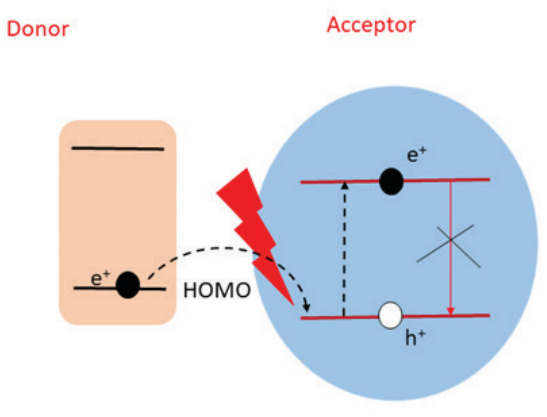

Nanoparticle

Figure 1. A comparison of FRET mechanism (A) and ET mechanism (B) between nanoparticles and biological molecules, being donors or acceptors.

Based on (Hassan et al., 2018; Lakowicz, 2007).

mon resonance energy transfer (PRET) is distinguished as a separate resonance energy transfer, due to the lack of fluorescence properties of the energy donor. Metallic nanoparticles are known to be excellent PRET examples. The principle of PRET is the oscillation of free electron, spatially confined within the physical boundaries of a nanoparticle (Liu et al., 2007a). This energy might be transferred to the acceptor molecule via dipole-dipole interactions, with a requirement that frequencies of donor and acceptor are matched (Cao et al., 2017). This basically means that plasmon resonance peak (measured as the maximum of optical density) of metallic nanoparticle and the absorption spectrum of the donor must overlap. The efficiency of PRET decreases with $\mathrm{R}^{4}$. Illuminated plasmonic nanoparticles may transfer the energy also via near field coupling and hot electron transfer. In general, those processes may be ascribed to nanosurface energy transfer (NSET) (Erwin et al., 2016).

Electron transfer between the molecules is a phenomenon which lies at the root of many life processes. In the simplest possible version it occurs between two molecules: a donor, giving out the electron, and an acceptor, receiving an electron. So the reaction occurs automatically with the change of the oxidation state - the donor is oxidized while the acceptor is reduced. The rates of electron transfer are described by Marcus theory (Marcus, 1956; Arnaut et al., 2006). The distance for the electron transfer to occur is much lower than the FRET range. However, it is quite often that electron transfer oc- curs over long distances, but with multiple steps. Those might include classic redox centres, but e.g. in proteins also amino acid side chains or even backbones might be involved. Also, the electron transfer may occur over long distances in DNA molecule, via $\pi$-stacks (Fukui \& Tanaka, 1998).

The direction of electron transfer is defined by the midpoint potential $\left(E_{m}\right)$ of redox centres. $E_{m}$ of redoxactive molecule is directly correlated to the energy of valence orbital and the energy gap. In nature, electron transfer and redox reaction are the basis of photosynthesis, mitochondrial respiration and many enzymatic reactions, catalysed by oxidoreductases. In the special case of photoinduced electron transfer ( $\mathrm{pET}$ ), the electron donor is excited after absorption of light, as it happens in FRET, but the energy is transferred by electron hopping between molecules. As a result, the donor contains a hole, which needs to be filled for the process to continue. In nature, the hole filling is realized e.g. by water splitting by oxygen evolving system, being a part of photosystem II (PSII). In artificial assays, the sacrificial electron donors (e.g. ascorbate) may be added if the longer performance is needed.

Macroscopically, both types of energy transfer may manifest by similar changes in fluorescent properties of the donor nanoparticles - the quenching of fluorescence intensity as well as a decrease of fluorescence lifetime. The difference manifests when the nanoparticle is on the acceptor side; the consequence of FRET is the enhance- 
ment of fluorescence intensity and increase of fluorescence lifetime. ET leads to quenching of fluorescence of the acceptor nanoparticles. Specific examples are described below.

\section{NANOPARTICLES USED FOR CONSTRUCTING BIONANOHYBRIDS}

Bionanohybrid-constructing kit contains a broad range of nanoparticles: semiconductor quantum dots (QDs), carbon-based nanoparticles including carbon nanodots (CDs) and graphene quantum dots (GQDs), metal nanoparticles, particularly colloidal gold and silver (AuNPs and AgNPs, respectively) and upconverting nanoparticles (UCNPs). In the next paragraphs, we briefly introduced them, referencing to more comprehensive reviews.

QDs are fluorescent nanocrystals of semiconductors optionally coated with high-band gap material (the most popular chemistry is CdSe core with $\mathrm{ZnS}$ shell) and capped with various organic ligands determining their colloidal features (Medintz et al., 2005; Blanco-Canosa et al., 2014)). Due to a quantum confinement effect, they exhibit size- and material-tuned emission with a broad absorption band (Michalet et al., 2005; Resch-Genger et al., 2008). The heavy metal QDs biotoxicity encouraged the development of fluorescent carbon-based materials. Different synthesis strategies provide a structural continuum of nanoparticles from graphene flake-like GQDs (including graphene oxide), through crystalline graphite particles, to amorphous CDs (Zheng \& Wu, 2017; Chen et al., 2019a). Their fluorescence emission, frequently excitation wavelength-dependent, may be regulated by heteroatom doping and $\mathrm{sp}^{2} / \mathrm{sp}^{3}$ carbon hybridization ratio.

The optical and electronic properties of metal nanoparticles origin from the localized surface plasmon resonance phenomenon - collective oscillating modes of conduction electrons, responsible for light absorption and resonance energy transfer (Zhan et al., 2018; Loiseau et al., 2019). The size and morphology of AuNPs and AgNPs determine the light absorption and scattering processes and the role of energy donor/acceptor in bionanosystems (Swierczewska et al., 2011).

UCNPs consist of lanthanides trivalent cations doping a transparent host nanocrystals, e.g. $\mathrm{NaYF}_{4}: \mathrm{Yb}, \mathrm{Y}_{2} \mathrm{O}_{2} \mathrm{~S}: \mathrm{Er}$ (Tu et al., 2015). They exhibit photon upconversion the process of sequential low energy-photons absorption followed by anti-Stokes emission of a single photon of higher energy. The energy upconversion can be realized by different mechanisms and controlled by doping and core-shell processing (Zhou et al., 2015).

\section{NANOBIOHYBRIDS WITH RESONANCE ENERGY TRANSFER}

In terms of luminescence energy transfer, the biological components of bionanohybrid systems can be utilized in two different ways: as an additional constituent besides the FRET donor-acceptor pair or directly as a participant of the energy transfer (Medintz et al., 2003; Dennis \& Bao, 2008). In most of examples, the first approach is in use and polypeptide or oligonucleotide is covalently linked to a low molecular weight organic dye or interacts with it in a receptor-ligand manner. Historically, the first examples of nanoparticle bioconjugates were based on the simple architectures (Willard et al., 2001; Dubertret et al., 2001). The energy transfer occurs between the nanoparticle and a small fluorophore and the biomolecule itself is not directly involved. In- stead, it acts as a mechanical scaffold or a spacer ensuring the assembly and the desired separation distances in the artificial complex (Pons et al., 2007; Kim et al., 2019). The simple bionanohybrid devices may also benefit from features specific for biological chemistry such as ligand recognition by proteins or hybridization of nucleic acids (Patolsky et al., 2003; Liu et al., 2007b; Field et al., 2018).

The relatively large and reactive surface of nanoparticles, enabling the conjugation to multiple copies of macromolecules, allowed to move beyond the conventional paired energy donor-acceptor configuration and to design networks of fluorophores and quenchers with more than one steps of energy transfer. In this chapter, we reviewed the recent advances in the development of biomolecules and nanoparticles conjugates, playing a role in chemical sensing, logical gating or enzymatic catalysis. Moreover, in contrast to labeling the biological component with an organic dye, we focused on the examples of systems which utilize intrinsically fluorescent biomolecules, mainly proteins, as adequate donors and acceptors of energy for nanoparticles. The so-created bionanohybrids may be used not only in applicative purpose but also provide a basic knowledge of photochemical and structural properties of proteins and nanomaterials.

\section{QUANTUM DOTS - FRET RELAYS AND LIGHT- HARVESTING COMPLEXES}

By far, QDs are nanoparticles which are the most often utilized in the construction of FRET systems, especially in the new classes of fluorescent nanohybrids. Among them are FRET cascade systems where electronic excitation energy is sequentially forwarded through the relay of fluorophores and 'one donor-one acceptor' scheme is abolished. Multistep photonic wires based on $\mathrm{CdSe} / \mathrm{ZnS}$ QDs and up to four cyanine dyes were created on the DNA scaffold (Boeneman et al., 2010; Spillmann et al., 2013). They utilized a remarkable feature of nucleic acids, which is the hybridization of complementary strands that facilitates a very precise spatial regulation of the fluorophores arrangement. These FRET cascades proceed from the central nanocrystal to the terminal acceptor over distances of around 15-18 nm. Optimization of spacing between the subsequent fluorophores as a function of Förster distance and increasing the number of DNA wires linked to QD allowed the energy transfer to reach $10 \%$ of the overall efficiency (Spillmann et al., 2013). To sum up, the relay in these examples extends the range of energy transfer and allows for a wavelength shift of the resulting emission.

The capability of natural systems, which are light-harvesting complexes of photosynthetic organisms, to perform sequential energy transfer, was also examined in the QDs bionanohybrids. CdSe/ZnS QDs, coated with negatively charged dihydrolipoic acid, interacted noncovalently and played the role of energy donor for the phycobiliprotein antenna of cyanobacterium Acaryochloris marina (Schmitt et al., 2012; Schmitt et al., 2011). This rod-shaped complex is formed by four linearly arranged hexameric units, three phycocyanin homohexamers and one phycocyanin-allophycocyanin heterohexamer, containing multiple copies of phycobilintetrapyrrole chromophores. The energy transfer is cold-sensitive and efficient by virtue of a high number of phycobilin acceptors per one antenna. The comparison of different cyanobacterial trimeric complexes, phycoerythrin, phycocyanin and allophycocyanin, showed different FRET efficiencies and dependency on QD diameter (Schmitt et al., 2012). What interesting, FRET rates 
did not correlate with $\mathrm{J} / \mathrm{R}^{6}$ parameter of Förster equation for FRET pairs with different QDs, which suggests that additional factors are crucial for the efficient energy transfer and the binding mode of phycobiliproteins can depend on QD size. In partial contradiction to the above, FRET between phycoerythrin-streptavidin conjugate and biotin-coated CdSe/ZnS QDs was reported to be agreeable to the Förster dipole-dipole formalism, with an efficiency that varied with the degree of spectral overlap and the distance between the donor and acceptor (Medintz et al. 2009). The large FRET efficiency of $60 \%$ resulted from the structure of the multichromophor phycoerythrine, containing multistep-FRET channels between the central QD and the phycobilin dyes distributed within the protein core. Taking into account the distance (counted from single steps in the multistep chain) between the donor and the final acceptor (from 10 to $12.5 \mathrm{~nm}$, depending on the phycoerythrin trimer position to the nanocrystal), the phycoerythrin-QD bioconjugate is a very efficient photonic nanowire, in comparison to the DNA-scaffolded systems (Spillmann et al., 2013). Closer investigation of FRET between allophycocyanin and QDs demonstrated a significant increase in energy transfer efficiency after monomerization of allophycocyanin trimers by high temperature or sodium thiocyanate chaotropic conditions (Karpulevich et al., 2016). Moreover, covalent linking and stabilization of bionanohybrid resulted in even further enhancement of allophycocyanin fluorescence upon excitation of QDs.

Similarly to their excitation relaying function in photosynthesis, light-harvesting complexes may also serve as energy donors for nanocrystal acceptors. Plant light-harvesting complex II (LHCII) trimer was found to be particularly interesting in this context due to its spontaneous self-organization and high extinction coefficient (Barros \& Kühlbrandt, 2009). The exact pigments system of LHCII consists of multiple copies of chlorophyll $a$ and $b$ and various carotenoids. LHCII from Pisum sativum was reported to efficiently transfer the excitation energy to the CdTe/ $\mathrm{CdSe} / \mathrm{ZnS}$ QDs with emission maximum at $760 \mathrm{~nm}$ after electrostatic attachment (Werwie et al., 2012). The increase in the light-energy utilization was particularly effective in the red region of the visible spectrum where QDs absorption is low. The overall absorptivity of the system was further improved by conjugation of LHCII to Alexa Fluor 555 dye absorbing in the green spectral domain where the window of transparency of chlorophyll is located.

In the opposition to the last paragraph, QDs can also play a role of light-harvesting particles as it was shown for the reaction center of the purple bacteria Rhodobacter sphaeroides (Nabiev et al., 2010). This protein heterotrimer comprises two branches of chromophores, active and inactive, each consisting of bacteriochlorophyll, bacteriopheophytin and quinone molecules, connected to the special pair of bacteriochlorophylls. In the noncovalent complex, the excitation energy of CdSe/ZnS QDs with peak emission at $570 \mathrm{~nm}$ is relayed through the reaction center and accepted by the special pair. Then, instead of splitting into an electron and a hole, in experimental conditions, the exciton decays with $910 \mathrm{~nm}$ emission. The energy transfer was efficient also in the assemblies of QDs and reaction center complexes in the lecithin liposomes and thin solid films (Lukashev et al., 2016).

\section{QUANTUM DOTS - CONCENTRIC FRET AND TIME- GATING}

Another convention followed in simple fluorescent bionanoconjugates which was broken in the recent ap- proaches is the rule of a single luminescent output signal. Although multiplexed FRET in this configuration is still possible, it requires multiple donors of energy and consequently usually more than one excitation wavelength. The main benefit of systems with more than one output may be the possibility of simultaneous detection of complex targets as well as the possibility to gain more insight into the single steps of multistep molecular processes. To obtain systems with more than one output signal, the advantage of the multivalence of QD surface was utilized. CdSe/ZnS QDs with peak emission at $520 \mathrm{~nm}$ were conjugated to two types of peptides labeled with Alexa Fluor 555 or Alexa Fluor 647 dyes (Algar et al., 2012). The single QD type was initial energy donor for both of the dyes, which were a FRET pair themselves. Hence, when QD was excited, $647 \mathrm{~nm}$-fluorophore was the final acceptor due to, firstly, direct energy transfer from QD and, secondly, through the FRET relay with $555 \mathrm{~nm}$-dye as the intermediate donor. The individual or simultaneous activities of trypsin and chymotrypsin, which recognize the proteolytic cleavage sites on the different peptides, could be assessed by comparison of 555/520 and 647/520 fluorescence intensity ratios. The same conjugate was used for sensing and imaging the diffusion of proteases in the glass capillary (Wu \& Algar, 2015). This co-called concentric FRET scheme was additionally extended by employing three molecular fluorophores, linked to the QD either by peptides with different protease recognition sites or oligonucleotides with different restriction sites (Massey et al., 2017; Hu et al., 2019).

The potency of concentric FRET architectures as energy donors was shown in the triple system of CdSe/ ZnS QD with $517 \mathrm{~nm}$ emission peak, enhanced yellow fluorescent protein (EYFP) and Atto647 dye (Lu et al., 2008). The fluorophores were assembled by DNA oligonucleotides hybridization which allowed for precise control of their separation. The interesting observation was that dominant QD-EYFP-Atto647 pathway was significantly more efficient than direct QD-Atto647 path in terms of energy transfer to the Atto647 terminal acceptor. This power of QD-EYFP conjugate as a FRET donor was assigned to the combined advantages of QDs (multivalence and spectrally broad absorption) and EYFP (high quantum yield).

The biological components of hybrid systems provide the possibility of light generation by chemiluminescence or, in the nomenclature preferred by some, bioluminescence. These self-illuminating systems do not require the source of excitation since the light emission is derived from the chemical reaction, not from the absorption of light. The source of chemiluminescence most popular in biochemical applications, luciferase enzyme (Thorne et al., 2010), was utilized in the bionanoconjugates based on BRET process. Catalyzing the oxidation of species-specific substrates (termed generically as luciferins) by molecular oxygen, luciferase may be a donor of luminescent energy directly for a QD. The BRET-FRET systems, consisting of luciferase-QD-red fluorescent protein (RFP) linear relay or luciferase-QD and molecular fluorophores concentric array, were designed (Alam et al., 2013; Samanta et al., 2015). Employing firefly luciferin producing bioluminescence at $547 \mathrm{~nm}$ and QDs absorbing at higher wavelengths enabled the direct BRET from luciferase to RFP and demonstrated the concept of transparent QD scaffold (Alam et al., 2013). The luciferase-QD BRET hybrids found practical utility in DNA sequence-sensing and tissue imaging (Kumar et al., 2011; Kamkaew et al., 2016). 
Multiplexing of signal in concentric FRET bionanosystems, especially significant in the context of sensing, may be achieved not only by differentiation of the signal wavelengths but also by separation of different emission lifetimes. The extremely long-lived fluorescent terbium complex was used as an energy donor in concentric assembly with CdSe/ZnS QD and Alexa Fluor 647 dye (Algar et al., 2012). The UV light flash excited both Tb complex and QD and two FRET processes could be observed: the first QD-Alexa Fluor 647 path in the first nanosecond period and the second Tb-QD-Alexa Fluor 647 transfer in the millisecond time window. The monitoring of fluorescence emission of the same wavelength with the microsecond time gate allowed distinguishing these two pathways which was utilized in the duplex assays for protease activity and oligonucleotides hybridization. Another approach was taken in miRNA hybridization sensor consisting of two oligonucleotide probes conjugated to a terbium complex and coupled with QD using different QD-Tb separation distances (Qiu et al., 2017a). Thus, the rate of FRET varied between the two probes which was reflected in different decay times. The distinction of signals was possible due to the fluorescence acquisition in two time windows.

\section{QUANTUM DOTS AND FLUORESCENT PROTEINS CONJUGATES AS SENSORS AND MOLECULAR MACHINES}

Combining QDs with biological elements results in systems with the attributes of both components: excellent optical properties of semiconductor nanocrystals and protein- or nucleic acid-based molecular recognition. Thus, the QD bionanoconjugates offer variable sensing strategies of applicative importance with FRET-induced emission as the detectable output (Medintz et al., 2003). In this section, we omitted the simple ligand-receptor detection approaches in favor of more advanced or unconventional sensing strategies.

Fluorescent proteins are particularly valuable in QD bionanosensors design. The example of QD complex with protein dimer associated by heterodimerizing, coiled-coil forming $\alpha$-helices, presented in our recent paper, demonstrated the most significant advantages of fluorescent proteins: the intrinsic emission without the requirement of dye-labeling, the ability of genetic recombination and one-step selfassembly to QDs (Sztatelman et al., 2019). The other instances include green fluorescent protein (GFP) containing trypsin cleavage site (Suzuki et al., 2008) and mCherry protein with N-terminal His-tag followed by caspase- 3 substrate sequence (Boeneman et al., 2009), coupled with CdSe/ZnS QDs. In both sensors, the proteolytic activity was determined by the decrease of QD-protein FRET signal. In the latter example, His-tag electrostatic interaction with nanocrystal surface allowed self-assembly by simple mixing of the two components and the fluorescence monitoring provided kinetic data and sensitive, quantitative detection.

The biocompatibility of proteins facilitates the use of bionanoconjugates as sensors of various physical and chemical quantities in vivo. The attribute of some GFP-family proteins, $\mathrm{pH}$-sensitivity, was utilized in the FRET probe comprising QD and mOrange protein or its mutant (Dennis et al., 2012). While under acidic conditions the energy transfer to mOrange acceptor was reported minimal, it was dramatically and reversibly enhanced with a $\mathrm{pH}$ increase. This sensor could measure $\mathrm{pH}$ in the range of $6-8$. After the delivery of the sensor to the cells, the temporal and spatial tracking of intracellular $\mathrm{pH}$ during endocytosis and translocation to the cytosol was demonstrated using fluorescence microscopy. A two-component voltage sensor was developed for imaging of another cellular quality, the electric potential of the plasma membrane (Chen et al., 2019b). Glutathione-capped QDs were used to label neural cells to serve as a FRET donor for lipophilic anionic fluorophore, dipicrilamine, which localizes at the positively charged site of the polarized membrane. The translocation of dipicrilamine within the lipid bilayer in response to the membrane potential changes the separation distance between FRET pair components which can be observed as the emission wavelength shift.

Beside sensing functions, the QD bionanohybrids may be engineered as photonic energy converters. QDs were shown to be FRET donors for bacteriorhodopsin of extremophile archaeon Halobacterium salinas (Rakovich et al., 2010). This retinal-containing proton pump forms trimers arranged in a semicrystalline lattice in the outer membrane of archaea, known as the purple membrane. Photon absorption triggers the isomerization of all-trans-retinal (peak absorption at $570 \mathrm{~nm}$ ) to the 13 -cis form, inducing the conformational changes of the polypeptide chain and the transport of a proton. The photocycle of bacteriorhodopsin occurs through a series of spectrally different intermediates (Li et al., 2018b). The energy transfer from QD donor significantly increases the rate of light-driven proton-pumping by bacteriorhodopsin. The efficiency of energy conversion and chemiosmotic potential formation was demonstrated by the incorporation of the bionanohybrid into the proteoliposomes (Rakovich et al., 2010). For bacteriorhodopsin, QDs play a role of light-harvesters, either in the UV range of spectrum or in the near-infrared region, in the latter case by virtue of the two-photon excitation process (do not confuse with photon upconvertion) which allows upconversion of the photonic energy and its transfer to the bacteriorhodopsin acceptor (Krivenkov et al., 2019).

\section{UPCONVERTING NANOPARTICLES - BIOSENSING AND NIR RADIATION HARVESTING}

UCNPs emitting NIR-induced fluorescence are of great interest as biocompatible components of nanosensors. NIR excitation light localizes in biologically transparent spectrum window, exhibits deep tissue penetration and allows to avoid cell phototoxicity and high background autofluorescence in the complex environment. UCNPs, with main emission maximum at $543 \mathrm{~nm}$, capped with ssDNA probes labeled with TAMRA dye and BHQ1 quencher were used for quantification and imaging of miRNA intracellular localization (Yang et al., 2019). After hybridization with miRNA target, complementary ssDNA probes detached from UCNP surface which resulted in an increase of $980 \mathrm{~nm}$-excited visible range fluorescence of UCNP. Dual acceptors enhanced quenching efficiency of UCNP and improved sensitivity of the assay. Another miRNA sensor comprised UCNPs assembled on silica beads and conjugated to molecular beacons probes labeled with FAM energy acceptor ( $\mathrm{Li}$ et al., 2019). Optical tweezers instrument allowed immobilization of the beads and precise imaging conditions.

An interesting example of bimodal UCNP nanosensor demonstrated the versatile possibility of UCNP emission tuning (Wilhelm et al., 2014). Single wavelength-excited UCNPs displayed emission spectrum with two bands (360 $\mathrm{nm}$ and $475 \mathrm{~nm}$ ) which perfectly overlapped with 
the absorption peaks of NADH and FAD coenzymes, respectively. The simultaneous monitoring of both coenzymes redox state was possible in the complex enzymatic reactions. Nonetheless, given the lack of nanoparticle lifetime changes and the average UCNP-coenzymes separation in solution exceeding any possible Förster distance, it was concluded that FAD or NADH did not act as energy acceptors but as emission screeners which resulted in an inner filter effect.

Upconversion of NIR radiation makes UCNPs promising candidates to play a role of light-harvesters facilitating the practical usage of the low-energy region of the light spectrum. After the incorporation into the bacteriorhodopsin-containing thin films of purple membranes, UCNPs may serve as energy donors (Lu et al., 2016). Two types of UCNPs with green and blue emission maxima accelerated particular transition steps of bacteriorhodopsin photocycle and profiling the green/blue emission ratio enabled to precisely control the proton pumping activity.

\section{CARBON NANOPARTICLES - IMPACT ON BIOMOLECULES CONFORMATION AND DNA-BASED NANOPROBES}

The luminescent energy transfer process was used to reveal interaction mechanisms of CDs with two primary biopolymers - proteins and DNA. Ruthenium-doped CDs, coated with amine groups, were shown to form noncovalent complexes with bovine and human serum albumins (BSA and HSA, respectively) and to perturb their secondary structure (Maity et al., 2019). The efficiency of FRET between tryptophan residues as donors and CDs acceptors was substantially higher for BSA which was assigned to the more rigid structure of BSA, in comparison to HSA, which in turn increases the stability of BSA-CD complex. Although molecular modeling confirmed the localization of tryptophan residues of both albumin proteins within a similar range from the CD surface, lower or equivalent to Förster distance, the fluctuations of polypeptide backbone were regarded to disturb the energy transfer more significantly in the case of HSA complex.

Nitrogen-doped CDs, capped with positively charged spermin, were also indicated to bind and induce a conformational change of DNA double helix (Feng et al., 2013). The binding target of spermin-coated carbon dots is the DNA helix major groove region, preferentially GC-rich sequences, which was shown by a competition assay with methyl green dye, major groove binder. The interaction with spermin-capped carbon dot triggered the transition of DNA structure from canonical right-handed B-form to left-handed Z-form, which is a transient structure induced by DNA-binding proteins and various molecular processes involving DNA, e.g. transcription and supercoiling. Such transition process was further investigated as the framework for the construction of several photonic logic gates. They were based on spermin-capped CDs, fluorescent DNA-intercalating agent ethidium bromide, and iodide ion as a potent quencher. Different combinations of those components resulted in various FRET and quenching processes, which in consequence led to various output fluorescence signals.

The doping of CDs with other elements may result in their dual-emissive characteristics and the improvement of FRET donor quality. Plant biomaterial-derived CDs, exhibiting excitation wavelength-independent emission maxima at $483 \mathrm{~nm}$ and $682 \mathrm{~nm}$, were examined as light-harvesters for photosystem complexes ( $\mathrm{Li}$ et al., 2018a). Due to blue and red emission bands, overlapping with chlorophyll absorption spectrum, CDs after the introduction to isolated chloroplast and intact leaves significantly accelerated the rate of photosynthesis. Unchanged lifetimes of CDs and chloroplasts indicated, though, that it was the reabsorption of CD-emitted light by chlorophyll that was responsible for the effect.

Despite repulsive electrostatic forces between negative charges, DNA-coupled graphene oxide-based nanoparticles are another class of bionanohybrids utilized as prototypic sensors. The reversible adsorption of ssDNA onto the graphene oxide surface is likely an effective outcome of several attractive forces: $\pi-\pi$ stacking, dehydration effect and hydrogen bonding (Paul et al., 2016). Hence, graphene oxide nanoparticles are extensively investigated as FRET quenchers in pair with adsorbed ssDNA fluorophore-labeled probes. As FRET bionanosensors, where detection is based on the cleavage or desorption of ssDNA and the increase of fluorescent signal, they were employed for exonuclease activity quantification (Liu et al., 2019), copper ions sensing by DNAzyme autocatalysis (Ding et al., 2018) or aptamer-dependent detection of toxins (Zhu et al., 2015).

\section{METAL NANOPARTICLES - PRET, NSET AND CHEMICAL NOSES}

The dependence of PRET on size and morphology of metal nanoparticle and on the PRET donor-acceptor distance separation was indicated in several studies of energy transfer between AuNPs or AgNPs and light-harvesting complexes. After the deposition of a thin film of the cyanobacterial trimer of photosystem I (PSI) from Synechococcus leopoliensis on the AgNP-coated glass, the increase of PSI fluorescence was observed (Kim et al., 2011). The PRET-induced enhancement zones were particularly localized near the aggregates of AgNPs. Surprisingly, the opposite results were obtained for covalent conjugates of AuNPs and AgNPs formed in solution by metal ions reduction in the presence of PSI (Carmeli et al., 2010). Both types of nanoparticles efficiently quenched the PSI fluorescence and enhanced light absorption on the entire range of PSI absorption spectrum, not only in the region of plasmon resonance wavelengths. This effect of absorption increase was assigned to the high dielectric constant near the metal surface. The inconsistency in terms of PRET-induced fluorescence quenching/enhancement in the both foregoing studies, despite the similar nanoparticle diameter $(\sim 10-20 \mathrm{~nm})$, could potentially result from a different orientation of bionanohybrid components i.e. separate layers of PSI and AuNPs versus exceptionally close and direct contact after in situ synthesis of the nanoparticles (Kim et al., 2011).

Similarly, the differences in the direction of energy transfer were shown for phycobiliproteins. The monolayers of several types of phycoerythrin, allophycocyanin and phycocyanin were immobilized on the glass coated with silver islands (100-500 nm diameter and $60 \mathrm{~nm}$ height) which resulted in the increase of the phycobiliproteins emission (Chowdhury et al., 2007). In the contradiction, phycoerythrin after mixing in solution with gold or silver nanoparticles (10 nm diameter), exhibited strong adsorption onto the metal surface and decrease of its fluorescence (Saraswat et al., 2011). It was proposed, that this discrepancy between the foregoing studies is a result of alternative energy transfer mechanisms. Differ- 
ent metal nanoparticles size can decide about their role as donors or acceptors of the energy (Swierczewska et al., 2011). In the first study, PRET from silver islands increased the emission of phycobiliproteins. In the latter case, the NSET mechanism of energy transfer from phycoerythrin to the metal surface could take place.

An interesting example of spatial gating of energy transfer and modulation of its efficiency was demonstrated on citric acid-coated AuNPs capped with survivin protein (Stobiecka \& Chalupa, 2015). As a result of FRET to the metal nanoparticle, the strong quenching of fluorescein isothiocyanate (FITC) was observed after mixing and FITC being several nanometers away from the gold surface. The total coverage of metal with survivin resulted in the partial fluorescence recovery due to hindrance for efficient energy transfer. The modulation of protein coverage allowed for regulation of efficiency of FRET from FITC to AuNP. The quantification of quenching efficiency in the dependence on protein concentration was proposed as a novel method for the determination of binding constants between proteins and nanoparticles.

The efficient PRET resulting in quenching of fluorescent proteins by metal nanoparticles was utilized in the multiplex chemical sensing method designed by Rotello's group (You et al., 2007). The assay principle consists of competitive displacement of fluorescent proteins or dyelabeled polymers from the metal nanoparticle by target molecules and the determination of fluorescence recovery. For various physicochemical properties (e.g. hydrophobicity, size, chemical affinities, electric charge) of the particular compound, the displacement capability differs. Using the array of AuNPs with different capping ligands complexed with various fluorescent proteins, it is possible to obtain target-specific pattern of fluorescence signals. So-performed fingerprinting was used for protein sensing (You et al., 2007; De et al., 2009; Xu et al., 2014), thiol compounds distinguishing (Kapur et al., 2017) and identifying anticancer drugs according to the protein profile on the cell surface (Rana et al., 2015). This 'chemical nose' combination of fluorescent bionanohybrid complexes loosely mimics the function of olfactory receptors in term of cross-reactivity and multivariate output.

\section{THE NANOHYBRIDS WITH ELECTRON TRANSFER}

Nanoparticles can be a source of (photo)electrons for biological reactions or a sink to electrons, generated during redox processes. The efficiency of such transfer is connected to $\mathrm{E}_{\mathrm{m}}$ of QDs and proteins (see e.g. (Grzyb et al., 2015)). The basic version of ET from QDs to an acceptor is the photoinduced formation of reactive oxygen species (ROS), which is one of the therapeutic strategies with application of nanoparticles. ROS production upon illumination was shown e.g. for CdSe QDs (Kauffer et al., 2014), CdTe QDs (Lovric et al., 2005), InPZnS QDs (Chibli et al., 2011) as well as GQDs (Ristic et al., 2014), Cd (Christensen et al., 2011) and AgNPs (Avalos et al., 2014). When oxygen is removed or excluded from the process, the ET from/to QDs becomes more interesting, with electron transferred to enzyme cofactors and other redox mediators.

\section{ET BETWEEN NANOPARTICLES AND REDOX BIOMOLECULES}

The most-used protein for electron transfer studies with various nanoparticles is probably glucose oxidase
(GOx). GOx catalyses the oxidation of glucose to gluconolactone, with the formation of hydrogen peroxide $\left(\mathrm{H}_{2} \mathrm{O}_{2}\right)$. This reactive oxygen form is a potential defence of fungi against microbes. The enzymatic reaction is possible due to the presence of flavin adenine dinucleotide cofactor, FAD, which gets reduced to FADH2 during glucose oxidation. Reoxidation of FAD demands the use of oxygen (Wilson \& Turner, 1992). This reaction is also used in enzymatic assays for oxygen removal, in tandem with catalase neutralizing $\mathrm{H}_{2} \mathrm{O}_{2}$ (see e.g. (Uppoor \& Niebergall, 1996)). In 2006, Protein Data Bank made it their molecule of the month because of this enzyme's enormous significance for biotechnological industries (Goodsell, 2006). GOx is basically one of the simplest tools for detection of glucose in blood samples for diabetes diagnosis and monitoring (Cash \& Clark, 2010). The same enzyme is also used in the food industry, for oxygen removal from fruits (e.g. to prevent apple puree browning (Parpinello et al., 2002)) or for glucose reduction in wine (Pickering et al., 1998). In combination with nanoparticles, the enzymatic performance of GOx may be influenced by electron transfer from nanoparticle to FAD with formation of FADH2 (inhibition of $\mathrm{GOx}$ ), or to the nanoparticle, helping to re-oxidase $\mathrm{FADH}_{2}$ to $\mathrm{FAD}$. Indirect influence is also possible, with some redox-active mediators. We can then distinguish direct electron transfer (dET) and indirect electron transfer (iET). dET from graphene to GOx inhibited its biosensing activity which in principle was caused by already-mentioned FAD reduction to $\mathrm{FADH}_{2}$ (Liang et al., 2015). CdSe/CdS quantum dots were shown to be excellent direct electron donors for GOx in electrochemical studies (Huang et al., 2008). Also, dET between multiwalled carbon nanotubes and GOx (Zhao et al., 2010), as well as carbon nitride nanosheets and GOx (Tian et al., 2019) was shown. In GOx conjugates with Mndoped $\mathrm{ZnS}$ QDs, iET plays a role in biosensing, with nanoparticles providing photoinduced electrons for $\mathrm{H}_{2} \mathrm{O}_{2}$ reduction and $\mathrm{O}_{2}$ restoring. When an electron is transferred from QDs, the fluorescence is quenched, which is the direct analytical signal (Wu et al., 2010). The same idea was applied using tungsten sulfide $\left(\mathrm{WS}_{2}\right)$ quantum dots (Duan et al., 2019). iET between CdS QDs and alkaline phosphatase was achieved with the mediation of 4-aminophenol, which is a product of enzymatic hydrolysis of p-aminophenol phosphate (Khalid et al., 2011). Thiocholine, being a product of enzymatic decomposition of acetylthiocholine by acetylcholine esterase, was reduced by the same QD type (Pardo-Yissar et al., 2003). Another mediator between CdSe/ZnS QDs and an enzyme, glucose dehydrogenase, was NADH (Schubert et al., 2009). In most of the cited biosensors, QDs are also immobilized on an electrode, which enables the measurement of generated photocurrent (Lisdat et al., 2013). dET occurred between multiwalled carbon nanotubes, decorated by gold nanoparticles, and the enzyme laccase (Lalaoui et al., 2016). This enzyme contains a redox center with four copper ions (Solomon et al., 1996), which enables the electron transfer. Our study showed the possibility of dET to the redox center of ferredoxin ( $F d)$ (Grzyb et al., 2015). Fd is a non-enzymatic protein, involved in several processes where it serves as an electron donor or mediator in redox pathways. Its redox cofactor, called iron-sulfur cluster, consists of two iron and two sulphur atoms, coordinated by four cysteine residues of the protein. Another iron-containing redox cofactor is heme, a prosthetic group of cytochromes, myoglobin and hemoglobins. dET between CdTe and cytochrome c (CytC) was shown for stable QD-CytC conjugates (Ger- 
hards et al., 2008) and for the transient complex between nanoparticle and protein (Grzyb et al., 2015). Our study showed that photoinduced electrons may be donated from QD conduction band as well as from defects, especially the surface ones (Darżynkiewicz et al., 2017). dET from CdTe to myoglobin resulted in deoxygenation of heme, which under $\mathrm{CO}$ atmosphere led to $\mathrm{CO}$ binding to the iron atom (Onoda et al., 2012). FAD, mentioned already in the description of GOx, is a common cofactor of redox-active enzymes. It is also a prosthetic group of ferredoxin: $\mathrm{NADP}^{+}$oxidoreductase (FNR), an enzyme catalyzing NADPH production during the light-dependent phase of photosynthesis. dET was observed for the covalent junction of CdSe QD and FNR (Brown et al., 2016). In this assay, dET resulted in FAD reduction but also in hole formation on the QD, which was then filled by the electron from ascorbic acid (Brown et al., 2016). Several other enzymes were conjugated to QDs, which resulted in altered enzyme kinetics (Breger et al., 2016). For example, in our FNR-CdSe/ZnS QDs covalent junction, dET was not proved, but the enzyme-substrate complex formation was easier, most probably due to the specific interaction with charged QD surface (Szczepaniak et al., 2013).

Phosphorescent Mn-doped ZnS QDs were conjugated to cetyltrimethylammonium bromide (CAB) an electron acceptor and also DNA intercalator. Without DNA in the mixture, photoinduced electrons are transferred to $\mathrm{CAB}$ and QDs emission is quenched. Restore of the phosphorescence is a signal of analyte presence (Miao et al., 2014). The same QDs, this time in junction with boronic-acid-substituted viologens, work as glucose detectors. This is possible due to the condensation of glucose with boronic acid into a tetrahedral anionic borate, which causes its detachment from the QDs surface (Miao et al., 2016). Folic acid (FA) was an electron donor for CdS/ZnS QDs, coated with polyethyleneimine, and this system was used for detection of FA receptors over HeLa cells (Zhang et al., 2012). While FA was assembled onto the QD surface, the QD fluorescence was quenched. Release of FA due to its higher affinity to cellular receptor resulted in restoring of QD emission.

\section{CARBON NANOPARTICLES AS EXCELLENT ET DONORS AND ACCEPTORS}

CDs, being simply clusters of carbon atoms, were shown to be excellent electron donors and acceptors (Wang et al., 2009). Fluorescence of $4.2 \mathrm{~nm}$ carbon QDs, with PEGylated surface, was quenched by nitrotoluene derivatives, which are model electron acceptors. The same nanoparticles, under illumination, were able to reduce anionic silver, acting as the electron donors. The CDs emission was also quenched by electron acceptor, N,N-diethylaniline (Wang et al., 2009). Graphene QDs, with the ability to donate photoelectrons to curcumin, were applied in a probe for Apo e4 DNA. After hybridization of the probe to the target oligonucleotide, the electron transfer rate was reduced, which was measured by the change in curcumin luminescence (Mars et al., 2018).

\section{METAL NANOCLUSTERS AS A SOURCE OF ELECTRONS}

Photoinduced electrons may be generated by illumination of silver nanoclusters. In the study on DNA/ AgNPs, photoelectrons were used for the reduction of hemin assembled with an oligonucleotide (G-quadruplex) (Zhang et al., 2013). ET manifested by quenching of nanoclusters fluorescence as well as significant shortening of fluorescence lifetime. The transfer rate was dependent on the distance between the donor and acceptor, and also the base pairs were involved in it by the $\pi$-stacking mechanism. When this design was enriched with specific aptamers against ATP, simple biosensor specifically detecting this nucleotide was obtained (Zhang et al., 2013). In a similar approach from the same group, CdTe/CdSe QDs, also conjugated to an oligonucleotide, were a source of photogenerated electrons for hemin acceptor. With aptamers specific for lysozyme, the design was used for this enzyme detection (Qiu et al., 2017b).

\section{NANOPARTICLES IN ET-DEPENDENT POTENTIAL SENSING}

Efros et al. considered electron transfer-based sensing of the electric field in neurons by QDs (Efros et al., 2018). In such an approach, QDs located outside the neuron membrane should be connected by some molecular wire to an electric field-sensitive electron donor or acceptor. Bioconjugates of $\mathrm{CdSe} / \mathrm{CdS} / \mathrm{ZnS}$ or $\mathrm{CdSe} / \mathrm{CdS} / \mathrm{CdZnS} /$ $\mathrm{ZnS}$ QDs and C-60 fullerene, connected via peptide linker, were successfully used for monitoring depolarization in HeLa cells (Nag et al., 2017). Decrease of luminescence upon depolarization occurred due to a preferential attraction of photoexcited electrons of QDs to C60 acceptor, while at resting membrane potential $(-70 \mathrm{mV})$ electrons recombined with holes of the excited nanoparticles (Nag et al., 2017). It is, however, known that even without electron transfer, the strong electric field may measurably quench QD luminescence, most probably due to the quantum-confined Stark effect. The observed changes are especially strong in small nanoparticles (radius $<2.5 \mathrm{~nm}$ ) which is related to the rate and yield of Auger recombination in such structures (Efros et al., 2018). The proof of that concept is e.g. a study with $\mathrm{ZnS} / \mathrm{CdSe}$ seeded nanorods sensing voltage of the HEK cells membranes (Park et al., 2019). The nanorods fluorescence quantum yield was correlated to the membrane potential. The emission intensity was higher at the native potential of -101.4 $\mathrm{mV}$ and decreased when ionophorevalinomycin was applied (Efros et al., 2018; Nag et al., 2017; Park et al., 2019).

\section{PHOTOSYNTHESIS AND ARTIFICIAL PHOTOSYNTHESIS WITH NANOPARTICLE-DEPENDENT ET}

Nanohybrids of QDs and photosynthetic apparatus need special attention because of their possible role in creating artificial photosynthetic systems. Photosynthetic membranes contain three types of redox pigment-protein complexes (photosystem I, photosystem II and cytochrome b6f complex), lipophilic redox mediator (plastoquinone) and water-soluble redox proteins (copper-containing plastocyanin and mentioned earlier ferredoxin and FNR). There are also non-redox active antennae of light-harvesting complexes, whose FRET-based interaction was described in the previous paragraphs. When considering possible donors or acceptors for ET, we have several candidates, depending on $\mathrm{E}_{\mathrm{m}}$ of the nanoparticle and redox-active biological molecule. Figure 2 compares $\mathrm{E}_{\mathrm{m}}$ of selected QDs with $E_{m}$ of photosynthetic redox centers. Simple dET is possible between QDs and quinones. Although plastoquinone has not been tested for ET with QDs yet, there are available studies on its analogues. 1,4-benzoquinone molecule ( $\mathrm{BBQ}$ ) is the simple model for plastoquinone. Illuminated $\mathrm{PbS}$ QDs were a source of photoinduced electrons, transferred at picosecond times- 


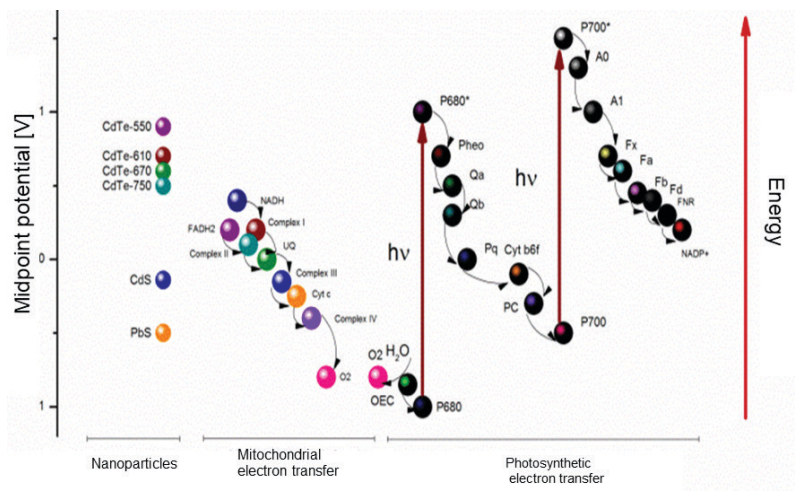

Figure 2. A comparison of the midpoint potential of selected nanoparticles and following steps of the mitochondrial and photosynthetic electron transfer chains.

It does not include Q-cycle and other possibilities of cyclic electron transfer. UQ - ubiquinone, Cyt c - cytochrome c, OEC - oxygen evolving complex, Pheo - pheophytin, QaiQb - quinones QaiQb in photosystem II, PQ - plastoquinone, Cyt b6f - cytochrome b6f complex; $\mathrm{A} 0, \mathrm{~A} 1, \mathrm{Fx}, \mathrm{Fa}, \mathrm{Fb}$ - following redox centres in photosystem I; PC - plastocyanin, Fd - ferredoxin, FNR ferredoxin:NADP+ oxidoreductase. The figure was prepared on the basis of (Blankenship, 2013; Douce, 2012; Grzyb et al., 2015; Rossetti et al., 1983; Cuharuc et al., 2012).

cale to covalently bound pBQ (Aruda et al., 2015; Knowles et al., 2012). The same molecules in solution were also reduced, just at a longer (nanosecond) timescale (Knowles et al., 2012). Donation of the electrons from hydroquinone, a reduced version of $\mathrm{pBQ}$, to QDs is also possible (Mo et al., 2018). With properly selected QDs it is then possible to demonstrate quinone cycles occurring in photosynthetic membranes. Ubiquinone, which is mitochondrial structural and functional analogue of plastoquinone, was used in assembly with CdSe/ZnS QD as a sensor of mitochondrial Complex I function (Ma et al., 2013). Mentioned earlier transfer to $\mathrm{Fd}$ is a part of the ET between QDs and the photosynthetic apparatus. Semiconductor QDs may be also included in the photoinduced multielectron transfer chains (Pannwitz \& Wenger, 2019).

Most of the studies of QDs-photosystems assemblies focused on FRET type energy transfer in those systems. It is worth to remember that, although not yet shown in the studies, in specific conditions QDs may not only be the antennae but also donors of an electron to the redox steps (QA, QB sites in PSII, A0, A1, Fx, Fa, Fb sites in PSII).

An interesting example, from the artificial photosynthesis point of view, is photoinduced electron transfer occurring in the conjugate of $\mathrm{QD}$ to pyridine derivative, 4,4'-bipyridium. This chemical in its reduced form is then able to reduce $\mathrm{CO}_{2}$ to methanol which is an interesting alternative for assimilation of atmospheric $\mathrm{CO}_{2}$ (Chen et al. 2016). This reaction may be considered as some kind of artificial photosynthesis, although not leading to carbohydrate synthesis. The challenge of $\mathrm{CO}_{2}$ reduction was also addressed with the nanohybrid of $\mathrm{ZnSe}$ QDs and a phosphonic acid-functionalised Ni(cyclam) catalyst (Neri et al., 2015). Photoinduced ET from CdSe/CdS QDs to platinum nanoparticles was shown to be the way to enhance catalytic hydrogen evolution (Li et al., 2017).

\section{COEXISTENCE OF FRET AND ET ROUTES IN BIONANOHYBRIDS}

Due to physical and chemical properties of nanoparticles, there is no formal restriction to only one type of energy transfer if acceptors specific to fluorescence energy transfer or electron transfer are present. The examples described above clearly showed that the same types of QDs can be both donors and acceptors for resonance energy transfer and for electron transfer. There are also studies, although rather sparse, where both types of transfers were involved. In the simple system with rhodamine, organic fluorophore, adsorbed on the QD surface, both FRET and electron transfer was present. Energy transfer manifested here by quenching QD fluorescence. The main pathway $(84 \%)$ could be ascribed to resonance energy transfer (Boulesbaa et al., 2009). Concurrent quenching of $\mathrm{CdSe} / \mathrm{ZnS}$ QDs fluorescence was observed by simultaneously attached fluorescent probe Cys and redox probe, ruthenium (II) phenanthroline (Algar et al., 2016).

The example of QD involved in FRET and ET was presented in a study where LHCII was shown to function as antennae for QDs $(\mathrm{CdTe} / \mathrm{CdSe} / \mathrm{ZnS})$ which in the following reaction were reducing methyl viologen (MV) (Werwie et al., 2018). In the presence of QDs, the MV photoreduction rate was increased at least twofold. In the cited paper, tris(2-carboxyethyl)phosphine/dihydrolipoic acid system was suggested to work as electron donor/hole regenerating system. Electron transfer component was as fast as 200 ps, faster than FRET component (500 ps) (Werwie et al., 2018). QDs were also used as antennae for bacteriorhodopsin in the hybrid system for photovoltaic applications (Renugopalakrishnan et al., 2014). Nanodevices for hydrogen evolution were constructed on the base of bacteriorhodopsin photosensitizing $\mathrm{TiO}_{2}$ nanoparticles by FRET mechanism with subsequent transfer of the electron from $\mathrm{TiO}_{2}$ to the connected platinum cluster and converting $\mathrm{H}^{+}$to $\mathrm{H}_{2}$. This resulted in a hole on $\mathrm{TiO}_{2}$, which was filled by decomposition of methanol to water and carbon dioxide (Wang et al., 2017).

Worth to mention example of both FRET and electron transfer is a self-assembled cascade of QDs, varying in size. Such a cascade was built on $\mathrm{TiO}_{2}$ electrode, which resulted in charge transfer detection by current measurement. Upon illumination, the excitons were transferred by QD of increasing size, to end up in electron donation to the electrode (Goodman et al., 2015).

\section{STRUCTURAL CHANGES WITHIN HYBRID PARTNERS}

Despite the mentioned changes in function, the formation of the junction between proteins and nanoparticles, especially semiconductor ones, may influence the structure of the biological element of the hybrid. The rationale for that is a known fact about protein denaturation in contact with abiotic surfaces. Proteins may bind nanoparticles nonspecifically, in that way forming a corona (Bhunia et al., 2013), which results in at least partial denaturation of the bound proteins. This is due to a strong interaction of some amino acids with heavy metal and transition metal ions, like cadmium, lead or zinc. Charged surfaces may disturb protein stability by attracting charged amino acid residues. To some extent, this is also true for hydrophobic surfaces interacting with hydrophobic patches of proteins. Molecular dynamics simulation dealt with this problem. Several papers showed small deformations of selected proteins near the surfaces of mica, zinc oxide, zinc sulfide and gold (Nawrocki \& Cieplak, 2013; Nawrocki \& Cieplak, 2014b; Nawrocki \& Cieplak, 2014a; Starzyk \& Cieplak, 2011). On the other hand, strong specific contact may be desired, to form 
protecting cover for nanoparticle or to allow distancedependent energy transfer. Strong, quasi-specific contact is quite often realized by binding of positively charged protein tag (e.g. polyhistidine tail (Ipe \& Niemeyer, 2006; Ipe et al., 2006; Sapsford et al., 2009)). Such binding may be really strong $\left(K_{d} \sim 10^{-9} \mathrm{M}\right)$ (Sztatelman et al. 2019) and also provides a stable orientation of protein versus QD surface which is especially important for the efficiency of resonance energy transfer. The problem appears (Ipe \& Niemeyer, 2006; Ipe et al., 2006; Sapsford et al., 2009; Sztatelman et al., 2019) when the protein contains other positively charged patches. Another way to obtain specific orientation is to use more specific interaction, e.g. biotinylated proteins bind to nanoparticles decorated with streptavidin (Nehilla et al., 2005). Usually binding with tag preserves the secondary and tertiary structure of the protein (Ji et al., 2005) but results in a greater distance between the donor and acceptor thus decreasing the rate of energy transfer.

It is also possible to form a protein embrace for QDs using longer peptides and proteins (Dabrowska et al., 2016). We found in a recent study that $\alpha$-helical proteins (PUF) may perform better in such a job than $\beta$-sheet ones (LRR) (Kopeć et al., 2019; Dąbrowska et al., 2016). The secondary structure of helical proteins was only slightly disturbed, the tertiary structure had to be imposed though due to the adaptation to QD geometry. Fluorescence properties of QDs in such a hybrid were mostly preserved (Antoniak et al., 2019). Short hydrophobic helical peptides were used as additional functionalization, addressing QDs to the cell membrane (Nag et al., 2017).

\section{CONCLUSIONS}

Here we described, by several examples, the junctions of biological molecules and abiotic nanomaterials. The energy transfer in such junctions is possible by resonance energy transfer or by the electron transfer mechanism. Several types of the nanoparticle may function as donors or acceptors in both mechanisms: semiconductor quantum dots, other metallic nanoparticles as well as carbon nanomaterials. The biological partners may be proteins with fluorescent cofactors or redox cofactors, as well as simpler organic molecules with appropriate properties. Also, a switch between the first and the second mechanism may take place at the nanoparticles. Several described nanobiohybrids function as sensors of specific molecules or of the change in the environmental conditions ( $\mathrm{pH}$, temperature). Some of them may be considered as nanobiodevices for alternative energy sources. For sure there is a huge demand for further studies to fully understand the functioning of such conjunctions in more nature-like conditions, especially under the availability of both FRET and ET partners, in oxidised and reduced versions.

\section{REFERENCES}

Alam R, Zylstra J, Fontaine DM, Branchini BR, Maye MM (2013) Novel multistep BRET-FRET energy transfer using nanoconjugates of firefly proteins, quantum dots, and red fluorescent proteins. $\mathrm{Na}$ noscale 5: 5303-5306. https://doi.org/10.1039/c3nr01842c

Algar WR, Ancona MG, Malanoski AP, Susumu K, Medintz IL (2012) Assembly of a concentric förster resonance energy transfer relay on a quantum dot scaffold: Characterization and application to multiplexed protease sensing. ACS Nano 6: 11044-11058. https://doi. org/10.1021/nn304736j

Algar WR, Khachatrian A, Melinger JS, Huston AL, Stewart MH, Susumu K, Blanco-Canosa JB, Oh E, Dawson PE, Medintz IL (2016) concurrent modulation of quantum dot photoluminescence using a combination of charge transfer and forster resonance energy transfer: competitive quenching and multiplexed biosensing modality. J Am Chem Soc 139: 363-372. https://doi.org/doi.org/10.1021/ jacs.6b11042

Antoniak MA, Grzyb J, Nyk M (2019) Preserved two-photon optical properties of hydrophilic proteins-conjugated quantum dots. I Luminescence 209: 57-60. https://doi.org/10.1016/j.jlumin.2019.01.029

Arnaut LG, Formosinho SJ, Burrows H (2006) Chemical kinetics: from molecular structure to chemical reactivity. Elsevier. ISBN-10 0444521860

Aruda KO, Bohlmann Kunz M, Tagliazucchi M, Weiss EA (2015) Temperature-dependent permeability of the ligand shell of PbS quantum dots probed by electron transfer to benzoquinone. $J$ Phys Chem Lett 6: 2841-2846. https://doi.org/10.1021/acs.jpclett.5b01256

Avalos A, Haza AI, Mateo D, Morales P (2014) Cytotoxicity and ROS production of manufactured silver nanoparticles of different sizes in hepatoma and leukemia cells. I Appl Toxicol 34: 413-423. https:// doi.org/10.1002/jat.2957

Barros T, Kühlbrandt W (2009) Crystallisation, structure and function of plant light-harvesting Complex II. Biochim Biophys Acta - Bioenergetics 1787: 753-772. https://doi.org/10.1016/j.bbabio.2009.03.012

Bhunia A, Samanta P, Saha S, Kamilya T (2013) ZnO nanoparticleprotein interaction: Corona formation with associated unfolding. Appl Phys Lett 103: 143701. https://doi.org/10.1063/1.4824021

Blanco-Canosa JB, Wu M, Susumu K, Petryayeva E, Jennings TL, Dawson PE, Algar WR, Medintz IL (2014) Recent progress in the bioconjugation of quantum dots. Coordination Chem Rev vol 263-264: 101-137. https://doi.org/10.1016/j.ccr.2013.08.030

Blankenship RE (2013) Molecular mechanisms of photosynthesis. John Wiley \& Sons. https://doi.org/10.1002/9780470758472

Boeneman K, Mei BC, Dennis AM, Bao G, Deschamps JR, Mattoussi H, Medintz IL (2009) Sensing caspase 3 activity with quantum dot-fluorescent protein assemblies. J Am Chem Soc 131: 3828-3829. https://doi.org/10.1021/ja809721j

Boeneman K, Prasuhn DE, Blanco-Canosa JB, Dawson PE, Melinger JS, Ancona M, Stewart MH, Susumu K, Huston A, Medintz IL (2010) Self-assembled quantum dot-sensitized multivalent DNA photonic wires. J Am Chem Soc 132: 18177-18190. https://doi. org/10.1021/ja106465x

Bohlen J, Cuartero-González Á, Pibiri E, Ruhlandt D, FernándezDomínguez A, Tinnefeld P, Acuna GP (2019) Plasmon-assisted Förster resonance energy transfer at the single-molecule level in the moderate quenching regime. Nanoscale 11: 7674-7681. https://doi. org/10.1039/C9NR01204D

Boulesbaa A, Huang Z, Wu D, Lian T (2009) Competition between energy and electron transfer from CdSe QDs to adsorbed rhodamine B. J Phys Chem C 114: 962-969. https://doi.org/doi.org/10.1021/ jp909972b

Breger J, Walper S, Ancona M, Stewart M, Oh E, Susumu K, Medintz I (2016) Understanding the enhanced kinetics of enzyme-quantum dot constructs. MRS Adv 1: 3831-3836. https://doi.org/10.1557/ adv.2015.35

Brown KA, Wilker MB, Boehm M, Hamby H, Dukovic G, King PW (2016) Photocatalytic regeneration of nicotinamide cofactors by quantum dot-enzyme biohybrid complexes. Acs Catal 6: 2201-2204. https://doi.org/10.1021/acscatal.5b02850

Cao Y, Xie T, Qian RC, Long YT (2017) Plasmon resonance energy transfer: coupling between chromophore molecules and metallic nanoparticles. Small 13: 1601955

Carmeli I, Lieberman I, Kraversky L, Fan Z, Govorov AO, Markovich $G$, Richter S (2010) Broad band enhancement of light absorption in photosystem i by metal nanoparticle antennas. Nano Lett 10: 2069_ 2074. https://doi.org/10.1021/nl100254j

Cash KJ, Clark HA (2010) Nanosensors and nanomaterials for monitoring glucose in diabetes. Trends Mol Med 16: 584-593. https://doi. org/10.1016/j.molmed.2010.08.002

Chen BB, Liu ML, Li CM, Huang CZ (2019a) Fluorescent carbon dots functionalization. Adv Colloid Interface Sci 270: 165-190. Elsevier B.V. https://doi.org/10.1016/j.cis.2019.06.008

Chen G, Zhang Y, Peng Z, Huang D, Li C, Wang Q (2019b) Glutathione-capped quantum dots for plasma membrane labeling and membrane potential imaging. Nano Res: 1-6

Chen J, Wu K, Rudshteyn B, Jia Y, Ding W, Xie Z-X, Batista VS, Lian $\mathrm{T}$ (2016) Ultrafast photoinduced interfacial proton coupled electron transfer from cdse quantum dots to 4, 4'-bipyridine. J Am Chem Soc 138: 884-892. https://doi.org/10.1021/jacs.5b10354

Chibli H, Carlini L, Park S, Dimitrijevic NM, Nadeau JL (2011) Cytotoxicity of $\mathrm{InP} / \mathrm{ZnS}$ quantum dots related to reactive oxygen species generation. Nanoscale 3: 2552-2559. https://doi.org/10.1039/ c1nr10131e

Chowdhury MH, Ray K, Aslan K, Lakowicz JR, Geddes CD (2007) Metal-enhanced fluorescence of phycobiliproteins from heterogeneous plasmonic nanostructures. J Phys Chem C 111: 18856-18863. https://doi.org/10.1021/jp0731250 
Christensen IL, Sun Y-P, Juzenas P (2011) Carbon dots as antioxidants and prooxidants. J Biomed Nanotechnol 7: 667-676. https://doi. org/10.1166/jbn.2011.1334

Cuharuc A, Kulyuk L, Lascova R, Mitioglu A, Dikusar A (2012) Electrochemical characterization of $\mathrm{PbS}$ quantum dots capped with oleic acid and PbS thin films - a comparative study. Surface Enginee Appl Electrochem 48: 193-211. https://doi.org/doi.org/10.3103/ $\$ 1068375512030040$

Darżynkiewicz ZM, Pędziwiatr M, Grzyb J (2017) Quantum dots use both LUMO and surface trap electrons in photoreduction process. J Luminescence 183: 401-409. https://doi.org/10.1016/j.jlu$\min .2016 .11 .070$

Dąbrowska A, Nyk M, Worch R, Grzyb J (2016) Hydrophilic colloidal quantum dots with long peptide chain coats. Colloid Surface B 145 : 662-670. https://doi.org/10.1016/j.colsurfb.2016.05.081

De M, Rana S, Akpinar H, Miranda OR, Arvizo RR, Bunz UHF, Rotello VM (2009) Sensing of proteins in human serum using conjugates of nanoparticles and green fluorescent protein. Nature Chem 1: 461-465. https://doi.org/10.1038/nchem.334

Dennis AM, Bao G (2008) Quantum dot-fluorescent protein pairs as novel fluorescence resonance energy transfer probes. Nano Lett $\mathbf{8}$ 1439-1445. https://doi.org/10.1021/nl080358+

Dennis AM, Rhee WJ, Sotto D, Dublin SN, Bao G (2012) Quantum dot-fluorescent protein FRET probes for sensing intracellular $\mathrm{pH}$. ACS Nano 6: 2917-2924

Ding L, Xu B, Li T, Huang J, Bai W (2018) A “turn-on" fluorescence copper biosensor based on DNA cleavage-dependent graphene oxide-dsDNA-Cdte quantum dots complex. Sensors (Switzerland) 18 : https://doi.org/10.3390/s18082605

Douce R (2012) Mitochondria in Higher Plants: Structure, Function, and Biogenesis. Elsevier. https://doi.org/10.1016/B978-0-12-221280-2. X5001-X

Duan X, Liu Q, Wang G, Su X (2019) WS2 quantum dots as a sensitive fluorescence probe for the detection of glucose. I Luminescence 207: 491-496. https://doi.org/10.1016/j.jlumin.2018.11.034

Dubertret B, Calame M, Libchaber AJ (2001) Single-mismatch detection using gold-quenched fluorescent oligonucleotid. Nature Biotechnol 19: 365-370. https://doi.org/10.1038/86762

Efros AL, Delehanty JB, Huston AL, Medintz IL, Barbic M, Harris TD (2018) Evaluating the potential of using quantum dots for monitoring electrical signals in neurons. Nature Nanotechnol 13: 278. https://doi.org/10.1038/s41565-018-0107-1

Erwin WR, Zarick HF, Talbert EM, Bardhan R (2016) Light trapping in mesoporous solar cells with plasmonic nanostructures. Energy \& Environ Sci 9: 1577-1601

Feng L, Zhao A, Ren J, Qu X (2013) Lighting up left-handed Z-DNA: Photoluminescent carbon dots induce DNA B to $\mathrm{Z}$ transition and perform DNA logic operations. Nucleic Acids Res 41: 7987-7996. https://doi.org/10.1093/nar/gkt575

Field LD, Walper SA, Susumu K, Lasarte-Aragones G, Oh E, Medintz IL, Delehanty JB (2018) A quantum dot-protein bioconjugate that provides for extracellular control of intracellular drug release. Bioconjugate Chem 29: 2455-2467. https://doi.org/10.1021/acs. bioconjchem. 8 b00357

Fukui K, Tanaka K (1998) Distance dependence of photoinduced electron transfer in DNA. Angew Chem Int Ed 37: 158-161. https://doi. org/10.1002/(Sici) 1521-3773(19980202)37

Gerhards C, Schulz-Drost C, Sgobba V, Guldi DM (2008) Conjugating luminescent CdTe quantum dots with biomolecules. I Phys Chem B 112: 14482-14491. https://doi.org/10.1021/jp8030094

Goodman SM, Siu A, Singh V, Nagpal P (2015) Long-range energy transfer in self-assembled quantum dot-DNA cascades. Nanoscale 7 : 18435-18440. https://doi.org/10.1039/c5nr04778a

Goodsell D (2006) Molecule of the month: Glucose oxidase. https://doi. org/10.2210/rcsb_pdb/mom_2006_5

Grzyb J, Kalwarczyk E, Worch R (2015) Photoreduction of natural redox proteins by $\mathrm{CdTe}$ quantum dots is size-tunable and conjugation-independent. RSC Adv 5: 61973-61982. https://doi. org/10.1039/c5ra02900g

Hassan M, Gomes VG, Dehghani A, Ardekani SM (2018) Engineering carbon quantum dots for photomediated theranostics. Nano Res 11: $1-41$

Hu J, Liu MH, Zhang CY (2019) Construction of tetrahedral DNAquantum dot nanostructure with the integration of multistep förster resonance energy transfer for multiplex enzymes assay. ACS Nano 13: 7191-7201. https://doi.org/10.1021/acsnano.9b02679

Huang C, Liu S, Chen T, Li Y (2008) A new approach for quantitative determination of glucose by using $\mathrm{CdSe} / \mathrm{ZnS}$ quantum dots. Sensors and Actuators B: Chem 130: 338-342. https://doi.org/10.1016/j. snb.2007.08.021

Ipe BI, Niemeyer CM (2006) Nanohybrids composed of quantum dots and cytochrome P450 as photocatalysts. Angew Chem Int Ed Engl 45: 504-507. https://doi.org/10.1002/anie.200503084

Ipe BI, Shukla A, Lu H, Zou B, Rehage H, Niemeyer CM (2006) Dynamic light-scattering analysis of the electrostatic interaction of hexahistidine-tagged cytochrome P450 enzyme with semicon- ductor quantum dots. Chem Phys Chem 7: 1112-1118. https://doi. org/10.1002/cphc. 200500660

Ji X, Zheng J, Xu J, Rastogi VK, Cheng T-C, DeFrank JJ, Leblanc RM (2005) (CdSe) ZnS quantum dots and organophosphorus hydrolase bioconjugate as biosensors for detection of paraoxon. I Phys Chem B 109: 3793-3799. https://doi.org/10.1021/jp044928f

Jones GA, Bradshaw DS (2019) Resonance energy transfer: From fundamental theory to recent applications. Frontiers Physics 7: 100. https://doi.org/10.3389/fphy.2019.00100

Kamkaew A, Sun H, England CG, Cheng L, Liu Z, Cai W (2016) Quantum dot-NanoLuc bioluminescence resonance energy transfer enables tumor imaging and lymph node mapping: In vivo. Chem Commun 52: 6997-7000. https://doi.org/10.1039/c6cc02764d

Kapur A, Aldeek F, Ji X, Safi M, Wang W, Del Cid A, Steinbock O, Mattoussi H (2017) Self-assembled gold nanoparticle-fluorescent protein conjugates as platforms for sensing thiolate compounds via modulation of energy transfer quenching. Bioconjugate Chem 28: 678687. https://doi.org/10.1021/acs.bioconjchem.7b00006

Karpulevich AA, Maksimov EG, Sluchanko NN, Vasiliev AN, Paschenko VZ (2016) Highly efficient energy transfer from quantum dot to allophycocyanin in hybrid structures. I Photochem Photobiol B: Biol 160: 96-101. https://doi.org/10.1016/i.jphotobiol.2016.03.048

Kauffer F-A, Merlin C, Balan L, Schneider R (2014) Incidence of the core composition on the stability, the ROS production and the toxicity of CdSe quantum dots. I Hazardous Mat 268: 246-255. https:// doi.org/10.1016/j.jhazmat.2014.01.029

Khalid W, Göbel G, Hühn D, Montenegro J-M, Rivera-Gil P, Lisdat F, Parak WJ (2011) Light triggered detection of aminophenyl phosphate with a quantum dot based enzyme electrode. I Nanobiotechnol 9: 46. https://doi.org/10.1186/1477-3155-9-46

Kim I, Bender SL, Hranisavljevic J, Utschig LM, Huang L, Wiederrecht GP, Tiede DM (2011) Metal nanoparticle plasmon-enhanced light-harvesting in a photosystem i thin film. Nano Lett 11: 30913098. https:/ /doi.org/10.1021/nl2010109

Kim I, Song H, Kim C, Kim M, Kyhm K, Kim K, Oh JW (2019) Intermolecular distance measurement with TNT suppressor on the M13 bacteriophage-based Förster resonance energy transfer system. Sci Rep 9. https://doi.org/10.1038/s41598-018-36990-0

Knowles KE, Malicki M, Weiss EA (2012) Dual-time scale photoinduced electron transfer from $\mathrm{PbS}$ quantum dots to a molecular acceptor. J Am Chem Soc 134: 12470-12473. https://doi.org/10.1021/ ja3060222

Kopeć K, Pędziwiatr M, Gront D, Sztatelman O, Sławski J, Lazicka M, Worch R, Zawada K, Makarova K, Nyk M (2019) Comparison of $\alpha$-helix and $\beta$-sheet structure adaptation to a quantum dot geometry: toward the identification of an optimal motif for a protein nanoparticle cover. ACS Omega 4: 13086-13099. https://doi.org/10.1021/ acsomega.9b00505

Krivenkov V, Samokhvalov P, Nabiev I (2019) Remarkably enhanced photoelectrical efficiency of bacteriorhodopsin in quantum dot Purple membrane complexes under two-photon excitation. Biosensors Bioelectron 137: 117-122. https://doi.org/10.1016/j.bios.2019.05.009

Kumar M, Zhang D, Broyles D, Deo SK (2011) A rapid, sensitive, and selective bioluminescence resonance energy transfer (BRET)based nucleic acid sensing system. Biosensors Bioelectron 30: 133-139. https://doi.org/10.1016/j.bios.2011.08.043

Lakowicz JR (2007) Principles of fluorescence spectroscopy. Springer Science \& Business Media, New York

Lalaoui Nm, Rousselot-Pailley P, Robert V, Mekmouche Y, Villalonga R, Holzinger M, Cosnier S, Tron T, Le Goff A (2016) Direct electron transfer between a site-specific pyrene-modified laccase and carbon nanotube/gold nanoparticle supramolecular assemblies for bioelectrocatalytic dioxygen reduction. Acs Catal 6: 1894-1900. https://doi.org/10.1021/acscatal.5b02442

Li CY, Kang YF, Qi CB, Zheng B, Zheng MQ, Song CY, Guo ZZ, Lin Y, Pang DW, Tang HW (2019) Breaking through bead-supported assay: integration of optical tweezers assisted fluorescence imaging and luminescence confined upconversion nanoparticles triggered luminescent resonance energy transfer (LRET). Anal Chem 91: 7950-7957. https://doi.org/10.1021/acs.analchem.9b01941

Li W, Wu S, Zhang H, Zhang X, Zhuang J, Hu C, Liu Y, Lei B, Ma L, Wang X (2018a) Enhanced biological photosynthetic efficiency using light-harvesting engineering with dual-emissive carbon dots. Adv Funct Mat 28: 1-11. https://doi.org/10.1002/adfm.201804004

Li X-B, Gao Y-J, Wang Y, Zhan F, Zhang X-Y, Kong Q-Y, Zhao N-J, Guo Q, Wu H-L, Li Z-J (2017) Self-assembled framework enhances electronic communication of ultrasmall-sized nanoparticles for exceptional solar hydrogen evolution. J Am Chem Soc 139: 4789-4796. https://doi.org/10.1021/jacs.6b12976

Li YT, Tian Y, Tian H, Tu T, Gou GY, Wang Q, Qiao YC, Yang Y, Ren TL (2018b) A review on bacteriorhodopsin-based bioelectronic devices. Sensors (Switzerland) 18: 1-21. https://doi.org/10.3390/ s18051368

Liang B, Guo X, Fang L, Hu Y, Yang G, Zhu Q, Wei J, Ye X (2015) Study of direct electron transfer and enzyme activity of glucose oxi- 
dase on graphene surface. Electrochem Commun 50: 1-5. https://doi. org/10.1016/j.elecom.2014.10.016

Lisdat F, Schäfer D, Kapp A (2013) Quantum dots on electrodesnew tools for bioelectroanalysis. Anal Bioanal Chem 405: 3739-3752. https://doi.org/10.1007/s00216-013-6789-1

Liu GL, Long Y-T, Choi Y, Kang T, Lee LP (2007a) Quantized plasmon quenching dips nanospectroscopy via plasmon resonance energy transfer. Nature Methods 4: 1015

Liu H, Ye T, Mao C (2007b) Fluorescent carbon nanoparticles derived from candle soot. Angew Chem Int Ed 46: 6473-6475

Liu X, Wu Y, Wu X, Zhao JX (2019) A graphene oxide-based fluorescence assay for the sensitive detection of DNA exonuclease enzymatic activity. Analyst 144: 6231-6239. https://doi.org/10.1039/ C9AN01283D

Loiseau A, Asila V, Boitel-Aullen G, Lam M, Salmain M, Boujday S (2019) Silver-based plasmonic nanoparticles for and their use in biosensing. Biosensors 9: 78. MDPI AG. https://doi.org/10.3390/ bios 9020078

Lovric J, Cho SJ, Winnik FM, Maysinger D (2005) Unmodified cadmium telluride quantum dots induce reactive oxygen species formation leading to multiple organelle damage and cell death. Chem Biol 12: 1227-1234. https://doi.org/10.1016/j.chembiol.2005.09.008

Lu H, Schöps O, Woggon U, Niemeyer CM (2008) Self-assembled donor comprising quantum dots and fluorescent proteins for longrange fluorescence resonance energy transfer. I Am Chem Soc 130: 4815-4827. https://doi.org/10.1021/ja078243f

Lu Z, Wang J, Li R, Qiao Y, Zhou M, Li CM (2016) Controllable stationary photocurrents generated from a bacteriorhodopsin/upconversion nanoparticle-based bionanosystem under NIR illumination. Nanoscale 8: 18524-18530. https://doi.org/10.1039/c6nr06930d

Lukashev EP, Knox PP, Gorokhov VV, Grishanova NP, Seifullina NK, Krikunova M, Lokstein H, Paschenko VZ (2016) Purple-bacterial photosynthetic reaction centers and quantum-dot hybrid-assemblies in lecithin liposomes and thin films. I Photochemi Photobiol B: Biol 164: 73-82. https://doi.org/10.1016/i.jphotobiol.2016.09.009

Ma W, Qin L-X, Liu F-T, Gu Z, Wang J, Pan ZG, James TD, Long Y-T (2013) Ubiquinone-quantum dot bioconjugates for in vitro and intracellular complex I sensing. Sci Rep 3: 1537. https://doi. org/10.1038/srep01537

Maity A, Pal U, Chakraborty B, Sengupta C, Sau A, Chakraborty S, Basu S (2019) Preferential photochemical interaction of $\mathrm{Ru}$ (III) doped carbon nano dots with bovine serum albumin over human serum albumin. Int J Biol Macromol 137: 483-494. https://doi. org/10.1016/j.ijbiomac.2019.06.126

Marcus RA (1956) On the theory of oxidation-reduction reactions involving electron transfer. I. J Chem Phys 24: 966-978

Mars A, Hamami M, Bechnak L, Patra D, Raouafi N (2018) Curcumin-graphene quantum dots for dual mode sensing platform: Electrochemical and fluorescence detection of APOe4, responsible of Alzheimer's disease. Anal Chim Acta 1036: 141-146. https://doi. org/10.1016/j.aca.2018.06.075

Massey M, Kim H, Conroy EM, Algar WR (2017) Expanded quantum dot-based concentric förster resonance energy transfer: adding and characterizing energy-transfer pathways for triply multiplexed biosensing. J Phys Chem C 121: 13345-13356. https://doi.org/10.1021/ acs.jpcc. 7 b02739

Medintz IL, Clapp AR, Mattoussi H, Goldman ER, Fisher B, Mauro JM (2003) Self-assembled nanoscale biosensors based on quantum dot FRET donors. Nat Mater 2: 630-638. https://doi.org/10.1038/ nmat 961

Medintz IL, Pons T, Trammell SA, Mattoussi H (2009) Charge transfer between quantum dots and peptide-coupled redox complexes. NRL Rev: 189-193

Medintz IL, Tetsuo Uyeda H, Goldman ER, Mattoussi H Quantum dot bioconjugates for imaging, labelling and sensing. Nature Materials 4: 435-446. https://doi.org/10.1038/nmat1390

Miao Y, Yang M, Yan G (2016) Self-assembly of phosphorescent quantum dots/boronic-acid-substituted viologen nanohybrids based on photoinduced electron transfer for glucose detection in aqueous solution. RSC Adv 6: 8588-8593. https://doi.org/10.1039/ c5ra19911e

Miao Y, Zhang Z, Gong Y, Yan G (2014) Phosphorescent quantum dots/doxorubicin nanohybrids based on photoinduced electron transfer for detection of DNA. Biosens Bioelectron 59: 300-306. https://doi.org/10.1016/j.bios.2014.03.076

Michalet X, Pinaud FF, Bentolila LA, Tsay JM, Doose S, Li JJ, Sundaresan G, Wu AM, Gambhir SS, Weiss S (2005) Quantum dots for live cells, in vivo imaging, and diagnostics. Science 307: 538-544. https://doi.org/10.1126/science.1104274

Mo G, He X, Zhou C, Ya D, Feng J, Yu C, Deng B (2018) Sensitive detection of hydroquinone based on electrochemiluminescence energy transfer between the exited $\mathrm{ZnSe}$ quantum dots and benzoquinone. Sensors Actuators B: Chem 266: 784-792. https://doi. org/10.1016/j.snb.2018.03.187

Nabiev I, Rakovich A, Sukhanova A, Lukashev E, Zagidullin V, Pachenko V, Rakovich YP, Donegan JF, Rubin AB, Govorov AO
(2010) Fluorescent quantum dots as artificial antennas for enhanced light harvesting and energy transfer to photosynthetic reaction centers. Angewandte Chemie-International Edn 49: 7217-7221. https://doi. org/10.1002/anie.201003067

Nag OK, Stewart MH, Deschamps JR, Susumu K, Oh E, Tsytsarev V, Tang Q, Efros AL, Vaxenburg R, Black BJ (2017) Quantum dotpeptide-fullerene bioconjugates for visualization of in vitro and in vivo cellular membrane potential. ACS Nano 11: 5598-5613. https:// doi.org/10.1021/acsnano.7b00954

Nawrocki G, Cieplak M (2013) Amino acids and proteins at ZnO-water interfaces in molecular dynamics simulations. Phys Chem Chem Phys 15: 13628-13636. https://doi.org/10.1039/C3CP52198B

Nawrocki G, Cieplak M (2014a) Aqueous amino acids and proteins near the surface of gold in hydrophilic and hydrophobic force fields. J Phys Chem C 118: 12929-12943. https://doi.org/10.1021/ jp5030558

Nawrocki G, Cieplak M (2014b) Interactions of aqueous amino acids and proteins with the (110) surface of $\mathrm{ZnS}$ in molecular dynamics simulations. J Chem Phys 140: 03B601_601. https://doi. org/10.1063/1.4866763

Nehilla BJ, Vu TQ, Desai TA (2005) Stoichiometry-dependent formation of quantum dot-antibody bioconjugates: a complementary atomic force microscopy and agarose gel electrophoresis study. $J$ Phys Chem B 109: 20724-20730. https://doi.org/10.1021/jp052613+

Neri G, Walsh JJ, Wilson C, Reynal A, Lim JY, Li X, White AJ, Long NJ, Durrant JR, Cowan AJ (2015) A functionalised nickel cyclam catalyst for $\mathrm{CO} 2$ reduction: electrocatalysis, semiconductor surface immobilisation and light-driven electron transfer. Phys Chemi Chem Phys 17: 1562-1566. https://doi.org/10.1039/c4cp04871g

Onoda A, Himiyama T, Ohkubo K, Fukuzumi S, Hayashi T (2012) Photochemical properties of a myoglobin-CdTe quantum dot conjugate. Chem Commun (Camb) 48: 8054-8056. https://doi.org/10.1039/ c2cc33046f

Pannwitz A, Wenger OS (2019) Proton-coupled multi-electron transfer and its relevance for artificial photosynthesis and photoredox catalysis. Chem Commun 55: 4004-4014. https://doi.org/10.1039/ c9cc00821g

Pardo-Yissar V, Katz E, Wasserman J, Willner I (2003) Acetylcholine esterase-labeled CdS nanoparticles on electrodes: photoelectrochemical sensing of the enzyme inhibitors. J Am Chem Soc 125: 622-623. https://doi.org/10.1021/ja028922k

Park J, Kuo Y, Li J, Huang Y-L, Miller EW, Weiss S (2019) Improved surface functionalization and characterization of membrane targeted semiconductor voltage nanosensors. J Phys Chem Lett 10: 3906-3913. https://doi.org/10.1021/acs.jpclett.9b01258

Parpinello G, Chinnici F, Versari A, Riponi C (2002) Preliminary study on glucose oxidase-catalase enzyme system to control the browning of apple and pear purées. Lwt-Food Sci Technol 35: 239-243. https:/9 doi.org/10.1006/fstl.2001.9851

Patolsky F, Gill R, Weizmann Y, Mokari T, Banin U, Wiliner I (2003) Lighting-up the dynamics of telomerization and DNA replication by CdSe-ZnS quantum dots. J Am Chem Soc 125: 13918-13919. https://doi.org/10.1021/ja035848c

Paul T, Bera SC, Agnihotri N, Mishra PP (2016) Single-molecule FRET studies of the hybridization mechanism during noncovalent adsorption and desorption of DNA on graphene oxide. J Phys Chem B 120: 11628-11636. https://doi.org/10.1021/acs.jpcb.6b06017

Pickering G, Heatherbell D, Barnes M (1998) Optimising glucose conversion in the production of reduced alcohol wine using glucose oxidase. Food Res Int 31: 685-692. https://doi.org/10.1016/S09639969(99)00046-0

Pons T, Medintz IL, Sapsford KE, Higashiya S, Grimes AF, English DS, Mattoussi H (2007) On the quenching of semiconductor quantum dot photoluminescence by proximal gold nanoparticles. Nano Lett 7: 3157-3164. https://doi.org/10.1021/nl071729

Qiu X, Guo J, Jin Z, Petreto A, Medintz IL, Hildebrandt N (2017a) Multiplexed nucleic acid hybridization assays using single-FRETpair distance-tuning. Small 13: 1-6. https://doi.org/10.1002/ smll.201700332

Qiu Z, Shu J, He Y, Lin Z, Zhang K, Lv S, Tang D (2017b) CdTe/ CdSe quantum dot-based fluorescent aptasensor with hemin/Gquadruplex DNzyme for sensitive detection of lysozyme using rolling circle amplification and strand hybridization. Biosens Bioelectron 87: 18-24. https://doi.org/10.1016/j.bios.2016.08.003

Rakovich A, Sukhanova A, Bouchonville N, Lukashev E, Oleinikov V, Artemyev M, Lesnyak V, Gaponik N, Molinari M, Troyon M, Rakovich YP, Donegan JF, Nabiev I (2010) Resonance energy transfer improves the biological function of bacteriorhodopsin within a hybrid material built from purple membranes and semiconductor quantum dots. Nano Lett 10: 2640-2648. https://doi.org/10.1021/ nl1013772

Rana S, Le NDB, Mout R, Saha K, Tonga GY, Bain RES, Miranda OR, Rotello CM, Rotello VM (2015) A multichannel nanosensor for instantaneous readout of cancer drug mechanisms. Nature Nanotechnol 10: 65-69. https://doi.org/10.1038/nnano.2014.285 
Renugopalakrishnan V, Barbiellini B, King C, Molinari M, Mochalov K, Sukhanova A, Nabiev I, Fojan P, Tuller HL, Chin M (2014) Engineering a robust photovoltaic device with quantum dots and bacteriorhodopsin. J Phys Chem C 118: 16710-16717. https://doi. org/10.1021/jp502885s

Resch-Genger U, Grabolle M, Cavaliere-Jaricot S, Nitschke R, Nann $T$ (2008) Quantum dots versus organic dyes as fluorescent labels. Nature Methods 5: 763-775

Ristic BZ, Milenkovic MM, Dakic IR, Todorovic-Markovic BM, Milosavljevic MS, Budimir MD, Paunovic VG, Dramicanin MD, Markovic ZM, Trajkovic VS (2014) Photodynamic antibacterial effect of graphene quantum dots. Biomaterials 35: 4428-4435. https:// doi.org/10.1016/j.biomaterials.2014.02.014

Rossetti R, Nakahara S, Brus LE (1983) Quantum size effects in the redox potentials, resonance Raman spectra, and electronic spectra of CdS crystallites in aqueous solution. J Chem Phys 79: 1086-1088. https://doi.org/10.1063/1.445834

Samanta A, Walper SA, Susumu K, Dwyer CL, Medintz IL (2015) An enzymatically-sensitized sequential and concentric energy transfer relay self-assembled around semiconductor quantum dots. Nanoscale 7: 7603-7614. https://doi.org/10.1039/c5nr00828j

Sapsford KE, Farrell D, Sun S, Rasooly A, Mattoussi H, Medintz IL (2009) Monitoring of enzymatic proteolysis on a electroluminescentCCD microchip platform using quantum dot-peptide substrates. Sensors Actuators B: Chem 139: 13-21. https://doi.org/10.1016/j. snb.2008.07.026

Saraswat S, Desireddy A, Zheng D, Guo L, Lu HP, Bigioni TP, Isailovic D (2011) Energy transfer from fluorescent proteins to metal nanoparticles. J Phys Chem C 115: 17587-17593

Schmitt FJ, Maksimov EG, Hätti P, Weißenborn J, Jeyasangar V, Razjivin AP, Paschenko VZ, Friedrich T, Renger G (2012) Coupling of different isolated photosynthetic light harvesting complexes and $\mathrm{CdSe} / \mathrm{ZnS}$ nanocrystals via Förster resonance energy transfer. Biochim Biophys Acta - Bioenergetics 1817: 1461-1470. https://doi. org/10.1016/j.bbabio.2012.03.030

Schmitt FJ, Maksimov EG, Suedmeyer H, Jeyasangar V, Theiss C, Paschenko VZ, Eichler HJ, Renger G (2011) Time resolved temperature switchable excitation energy transfer processes between CdSe/ $\mathrm{ZnS}$ nanocrystals and phycobiliprotein antenna from Acaryochloris marina. Photonics Nanostructures - Fundamentals and Applications 9: 190195. https://doi.org/10.1016/j.photonics.2010.07.004

Schubert K, Khalid W, Yue Z, Parak WJ, Lisdat F (2009) Quantumdot-modified electrode in combination with NADH-dependent dehydrogenase reactions for substrate analysis. Langmuir 26: 13951400. https://doi.org/10.1021/la902499e

Solomon EI, Sundaram UM, Machonkin TE (1996) Multicopper oxidases and oxygenases. Chem Rev 96: 2563-2606. https://doi. org/10.1021/ cr950046o

Spillmann CM, Ancona MG, Buckhout-White S, Algar WR, Stewart MH, Susumu K, Huston AL, Goldman ER, Medintz IL (2013) Achieving effective terminal exciton delivery in quantum dot antenna-sensitized multistep DNA photonic wires. ACS Nano 7: 71017118. https://doi.org/10.1021/nn402468t

Starzyk A, Cieplak M (2011) Denaturation of proteins near polar surfaces. J Chem Phys 135: 12B615. https://doi.org/10.1063/1.3665930

Stobiecka M, Chalupa A (2015) Modulation of plasmon-enhanced resonance energy transfer to gold nanoparticles by protein survivin channeled-shell gating. J Phys Chem B 119: 13227-13235. https://doi. org/10.1021/acs.jpcb.5b07778

Suzuki M, Husimi Y, Komatsu H, Suzuki K, Douglas KT (2008) Quantum dot FRET biosensors that respond to $\mathrm{pH}$, to proteolytic or nucleolytic cleavage, to DNA synthesis, or to a multiplexing combination. $J$ Am Chem Soc 130: 5720-5725. https://doi. org/10.1021/ja710870e

Swierczewska M, Lee S, Chen X (2011) The design and application of fluorophore-gold nanoparticle activatable probes. Phys Chem Chem Phys 13: 9929-9941

Szczepaniak K, Worch R, Grzyb J (2013) Ferredoxin:NADP(+) oxidoreductase in junction with $\mathrm{CdSe} / \mathrm{ZnS}$ quantum dots: characteristics of an enzymatically active nanohybrid. J Phys: Condens Matter 25: 19. https://doi.org/10.1088/0953-8984/25/19/194102

Sztatelman O, Kopeć K, Pędziwiatr M, Trojnar M, Worch R, WielgusKutrowska B, Jemioła-Rzemińska M, Bzowska A, Grzyb J (2019) Heterodimerizing helices as tools for nanoscale control of the organization of protein-protein and protein-quantum dots. Biochimie 167: 93-105. https://doi.org/10.1016/j.biochi.2019.09.015

Thorne N, Inglese J, Auld DS (2010) Illuminating insights into firefly luciferase and other bioluminescent reporters used in chemical biology. Chem Biol 17: 646-657. https://doi.org/10.1016/j.chembiol.2010.05.012

Tian K, Liu H, Dong Y, Chu X, Wang S (2019) Amperometric detection of glucose based on immobilizing glucose oxidase on $g$ -
C3N4 nanosheets. Colloids Surfaces A: Physicochem Enginee Aspects 581: 123808. https://doi.org/10.1016/j.colsurfa.2019.123808

Tu L, Liu X, Wu F, Zhang H (2015) Excitation energy migration dynamics in upconversion nanomaterials. Chem Soc Rev 44: 1331-1345. https://doi.org/10.1039/c4cs00168k

Uppoor R, Niebergall PJ (1996) $\beta$-D (+) glucose-glucose oxidasecatalase for use as an antioxidant system. Pharm Develop Technol 1: 127-134. https://doi.org/10.3109/10837459609029887

Wang P, Chang AY, Novosad V, Chupin VV, Schaller RD, Rozhkova EA (2017) Cell-free synthetic biology chassis for nanocatalytic photon-to-hydrogen conversion. ACS Nano 11: 6739-6745. https://doi. org/10.1021/acsnano.7b01142

Wang X, Cao L, Lu F, Meziani MJ, Li H, Qi G, Zhou B, Harruff BA, Kermarrec F, Sun Y-P (2009) Photoinduced electron transfers with carbon dots. Chem Commun: 3774-3776. https://doi.org/10.1039/ b906252a

Werwie M, Dworak L, Bottin A, Mayer L, Basché T, Wachtveitl J, Paulsen H (2018) Light-harvesting chlorophyll protein (LHCII) drives electron transfer in semiconductor nanocrystals. Biochim Biophys Acta (BBA) - Bioenergetics 1859: 174-181. https://doi. org/10.1016/i.bbabio.2017.12.001

Werwie M, Xu X, Haase M, Basché T, Paulsen H (2012) Bio serves nano: Biological light-harvesting complex as energy donor for semiconductor quantum dots. Langmuir 28: 5810-5818. https://doi, org/10.1021/la204970a

Wilhelm S, Del Barrio M, Heiland J, Himmelstoß SF, Galbán J, Wolfbeis OS, Hirsch T (2014) Spectrally matched upconverting luminescent nanoparticles for monitoring enzymatic reactions. ACS Appl Mat Interfaces 6: 15427-15433. https://doi.org/10.1021/am5038643

Willard DM, Carillo LL, Jung J, Van Orden A (2001) CdSe-ZnS quantum dots as resonance energy transfer donors in a model proteinprotein binding assay. Nano Lett 1: 469-474

Wilson R, Turner A (1992) Glucose oxidase: an ideal enzyme. Biosens Bioelectron 7: 165-185. https://doi.org/10.1016/0956-5663(92)87013$\mathrm{F}$

Wu M, Algar WR (2015) Concentric Förster Resonance Energy Transfer Imaging. Anal Chem 87: 8078-8083. https://doi.org/10.1021/ acs.analchem.5b01946

Wu P, He Y, Wang H-F, Yan X-P (2010) Conjugation of glucose oxidase onto Mn-doped ZnS quantum dots for phosphorescent sensing of glucose in biological fluids. Anal Chem 82: 1427-1433. https://doi.org/10.1021/ac902531g

Xu S, Lu X, Yao C, Huang F, Jiang H, Hua W, Na N, Liu H, Ouyang J (2014) A visual sensor array for pattern recognition analysis of proteins using novel blue-emitting fluorescent gold nanoclusters. Anal Chem 86: 11634-11639. https://doi.org/10.1021/ac502643s

Yang L, Zhang K, Bi S, Zhu J-J (2019) Dual-acceptor-based upconversion luminescence nanosensor with enhanced quenching efficiency for in situ imaging and quantification of microRNA in living cells. ACS Appl Mat Interfaces 11: 38459-38466. https://doi.org/10.1021/ acsami. $9 \mathrm{~b} 12254$

You CC, Miranda OR, Gider B, Ghosh PS, Kim IB, Erdogan B, Krovi SA, Bunz UHF, Rotello VM (2007) Detection and identification of proteins using nanoparticle-fluorescent polymer 'chemical nose' sensors. Nature Nanotechnol 2: 318-323. https://doi.org/10.1038/ nnano. 2007.99

Zhan C, Chen XJ, Yi J, Li JF, Wu DY, Tian ZQ (2018) From plasmon-enhanced molecular spectroscopy to plasmon-mediated chemical reactions. Nature Rev Chem 2: 216-230. https://doi.org/10.1038/ s41570-018-0031-9

Zhang L, Zhu J, Guo S, Li T, Li J, Wang E (2013) Photoinduced electron transfer of DNA/Ag nanoclusters modulated by G-quadruplex/hemin complex for the construction of versatile biosensors. J Am Chem Soc 135: 2403-2406. https://doi.org/10.1021/ja3089857

Zhang Y, Liu J-M, Yan X-P (2012) Self-assembly of folate onto polyethyleneimine-coated $\mathrm{CdS} / \mathrm{ZnS}$ quantum dots for targeted turn-on fluorescence imaging of folate receptor overexpressed cancer cells. Anal Chem 85: 228-234. https://doi.org/10.1021/ac3025653

Zhao H-Z, Sun J-J, Song J, Yang Q-Z (2010) Direct electron transfer and conformational change of glucose oxidase on carbon nanotubebased electrodes. Carbon 48: 1508-1514. https://doi.org/10.1016/j. carbon.2009.12.046

Zheng P, Wu N (2017) Fluorescence and sensing applications of graphene oxide and graphene quantum dots: a review. Chemistry - An Asian J 12: 2343-2353. https://doi.org/10.1002/asia.201700814

Zhou B, Shi B, Jin D, Liu X (2015) Controlling upconversion nanocrystals for emerging applications. Nature Nanotechnol 10: 924-936. https://doi.org/10.1038/nnano.2015.251

Zhu Y, Cai Y, Xu L, Zheng L, Wang L, Qi B, Xu C (2015) Building an aptamer/graphene oxide FRET biosensor for one-step detection of bisphenol A. ACS Appl Mat Interfaces 7: 7492-7496. https://doi. org/10.1021/acsami.5b00199 